\title{
The Power of Numbers: Base-Ten Threshold Effects in Reported Revenue
}

\author{
Derrald Stice* \\ School of Business and Management \\ Hong Kong University of Science and Technology \\ acstice@ust.hk \\ Earl K. Stice \\ Graduate School of Business \\ Nazarbayev University (Astana, Kazakhstan) \\ and \\ Marriott School of Management \\ Brigham Young University \\ eks@byu.edu \\ Han Stice \\ Warrington College of Business Administration \\ University of Florida \\ han.stice@warrington.ufl.edu \\ Lorien Stice-Lawrence \\ Kenan-Flagler Business School \\ University of North Carolina at Chapel Hill \\ lorien_stice@kenan-flagler.unc.edu
}

Draft: March 2016

We appreciate comments and suggestions from Dan Amiram, Erv Black, Zahn Bozanic, Ted Christensen, Kyle Peterson, Roy Schmardebeck, Tim Seidel, participants at the BYU Accounting Research Symposium, and workshop participants at Nazarbayev University. Professor E.K. Stice acknowledges financial support from the EY Professorship at Nazarbayev University and the PricewaterhouseCoopers Professorship at Brigham Young University.

*Address for correspondence: Department of Accounting, School of Business and Management, Hong Kong University of Science and Technology, Clear Water Bay, Kowloon, Hong Kong. Phone: 852-2358-7556. Email: acstice@ust.hk. 


\title{
The Power of Numbers: Base-Ten Threshold Effects in Reported Revenue
}

\begin{abstract}
We provide evidence that managers have a revealed preference for reporting total revenue numbers just above base-ten thresholds (i.e., "round" numbers) of the form $\mathrm{N} \times 10^{\mathrm{K}}$. Examples are $\$ 10$ million $\left(1 \times 10^{7}\right)$ and $\$ 4$ billion $\left(4 \times 10^{9}\right)$. Our finding is consistent with a literature in psychology demonstrating that humans are susceptible to a cognitive bias associated with baseten reference points. However, we also document several rational explanations for this revenue management behavior on the part of managers. First, analyst revenue forecasts also exhibit this regularity, especially in early forecasts when greater uncertainty can potentially induce analysts to rely to a greater extent on heuristics, suggesting that managers may be managing reported revenue numbers to meet externally-determined base-ten-influenced benchmarks. In addition, the effect that we document is stronger for firms that face greater pressure to report high revenue growth, while firms that exceed base-ten revenue thresholds for the first time benefit from increased press coverage. Finally, we show that the revenue growth needed to stretch for a baseten threshold is not sustainable; firms that just exceed base-ten thresholds have lower subsequent revenue growth. Given that managers engage in extra, and, on average, unsustainable efforts to increase revenues to reach base-ten thresholds, our results suggest that revenue manipulation is even more pervasive than previously documented and that lenders, investors, auditors, and regulators should apply an extra degree of skepticism when a reported revenue number just exceeds a base-ten threshold.
\end{abstract}

Key words: Revenue Management, Base-Ten Thresholds, Analyst Forecast Heuristics, Revenue Quality 


\section{Introduction}

The existence of salient numbers, or cognitive reference points, at base-ten thresholds (i.e., "round" numbers) has been well documented in the psychology literature. These base-ten thresholds take the general form of $\mathrm{N} \times 10^{\mathrm{K}}$, where $\mathrm{N}$ and $\mathrm{K}$ are integers. Examples are $\$ 1$ million $\left(1 \times 10^{6}\right), \$ 300$ million $\left(3 \times 10^{8}\right), \$ 7$ billion $\left(7 \times 10^{9}\right)$, and so forth. Gabor and Granger (1966) and Rosch (1975) conclude that humans use numbers that are factors of ten as reference points when evaluating all other numbers. Schindler and Wiman (1989) suggest that round numbers are easier to remember and come to mind more readily, and Tversky and Kahneman (1973) find that when making decisions individuals give excess weight to information that is easily retrieved from memory. In this paper, we study the extent to which firms manage their reported accounting numbers in order to report revenue just above base-ten thresholds, and we provide evidence on some of the motivations and consequences associated with firms engaging in this revenue management behavior.

Managers may desire to report revenues above a base-ten threshold for several reasons. Research in psychology and marketing demonstrates that consumers view prices ending in 99 cents to be substantially lower than prices just one cent above (Brenner and Brenner 1982). This same cognitive bias may lead investors to value a company with $\$ 99$ million in revenue substantially lower than an otherwise-similar company with $\$ 100$ million in revenue. Additionally, a cognitive bias among investors, analysts, and business reporters may lead to an increase in visibility for firms reaching a base-ten threshold point. Firms that report revenues that meet or just beat a base-ten threshold may be more likely to capture the attention of investors and the financial press. This increase in attention could then lead to a net increase in buying by individual investors and a net increase in coverage by the media (Odean 1998; Barber and Odean 2008). 
These human perception explanations imply that there could be a disproportionate number of firms reporting revenue just above rather than just below base-ten thresholds as a result of opportunistic actions by managers exploiting a cognitive bias of investors, analysts, and business reporters. If this cognitive bias is prevalent among financial market participants, it would be rational for a manager to expend money and effort to reach a base-ten revenue threshold in order to attract more market attention or to enhance firm valuation. Possible consequences of this threshold-reaching revenue management behavior by managers are that reported revenues falling in these base-ten-related regions could be less reliable because they are more susceptible to strategic reporting by managers and could also be less persistent because they are achieved through unsustainable real activities or accruals management.

Empirically, we use approximate randomization techniques to show that firms are significantly more likely to report revenues just above base-ten thresholds (\$10 million, \$200 million, $\$ 7.0$ billion, and so forth) than just below them. This base-ten revenue threshold effect exists independent of the reporting currency; our results hold for firms reporting in U.S. dollars and for firms reporting in a variety of non-U.S. currencies. We also find that the base-ten threshold effect exists in analysts' forecasts of revenue and this effect is strongest in the earliest revenue forecasts, made when uncertainty about future revenues is the highest. This suggests that part of managers' motivation to beat base-ten revenue thresholds may be a rational response to meet important external benchmarks. Additionally, we find that firms which reach the $\$ 500$ million or $\$ 1$ billion revenue thresholds for the first time experience an increase in news coverage relative to the prior year and to a matched control sample, again indicating that rational managers have an incentive to reach a base-ten revenue threshold in order to increase firm visibility. We also find that this revenue threshold effect is stronger for firms with high past and 
expected future revenue growth (firms for which revenue growth is often a key performance indicator). Lastly, we find that threshold-reaching firms experience lower revenue growth in the subsequent year compared to a control sample, suggesting that the increased revenue growth needed to reach a base-ten threshold is not sustainable.

Our study has important implications for practitioners and academics. First, we document the existence of a base-ten threshold effect in reported revenues. Although prior research has documented a preference for base-ten thresholds in reported earnings (Carslaw 1988; Thomas 1989), this result has not previously been documented with respect to revenue, an important metric in its own right. After earnings, revenues are the accounting number most widely followed by investors and analysts (Rees and Sivaramakrishnan 2007), and revenues have long been known to contain incremental information content beyond earnings (Swaminathan and Weintrop 1991; Davis 2002; Jegadeesh and Livnat 2006). Additionally, revenues are closely tied to future firm growth, and Ghosh et al. (2005) find that increases in earnings that are accompanied by revenue growth tend to be more persistent. However, recent research such as Dichev et al. (2013) has stressed the "one number" mentality of managers who focus on bottom line net income as the single most important number for internal decision-making and external reporting. With such a mentality, managers might care about reported revenue only to the extent that it impacts bottom-line net income. Our results provide evidence that the level of reported revenue itself is an important reporting metric to managers, independent of the contribution of revenue to overall income, and that the level of the reported revenue number is an object of strategic management.

Second, our study provides novel evidence on both the motives and consequences of meeting base-ten thresholds. Thomas (1989) proposes two potential explanations for a base-ten 
preference in reported accounting numbers-the "firm valuation perspective" which is that the market places a higher value on firms reporting round numbers and the "contractual parameter perspective" which is that contracts are often denominated in round numbers-but does not empirically test either of these theories. Our analyst, media, and expected revenue growth analyses provide evidence in general support of both of these theories. In addition, our results on realized future revenue growth provide a note of caution that the methods used to meet these base-ten revenue benchmarks result in reported revenue growth that is not sustainable.

Finally, examining the base-ten threshold effect in revenues provides another avenue for exploring the quality of reported income-related numbers that is not possible from studying the distribution of earnings directly. By documenting the existence of revenue management around a large set of base-ten thresholds, we demonstrate the pervasive nature of benchmark-meeting behavior among managers. This result suggests that financial statement users should scrutinize the quality of both the revenue number and the earnings number in an income statement containing revenues just exceeding a base-ten threshold. In its Staff Accounting Bulletin No. 99 titled "Materiality" (SEC 1999), the Securities and Exchange Commission notes that small changes in reported amounts may be material when those changes can influence or alter the impression those reported amounts make on the financial statement user. In that context, and given the significance of base-ten thresholds in the human decision-making process, base-ten threshold-reaching efforts by managers can constitute a material change to the reported revenue numbers.

Our results imply that revenue numbers that just exceed a base-ten threshold should be cautiously interpreted in all contexts. The numbers that we study come from audited financial statements, so the base-ten threshold effect exists even in the presence of revenue management 
constraints stemming from auditor oversight. It is likely that this base-ten threshold phenomenon also exists in the financial statements of privately-held businesses which are not subject to mandatory audits, and in internal accounting numbers such as revenue budgets, targets, and internal forecasts that are not externally reported. In short, given that audited numbers of publicly-traded companies are subject to high levels of outside monitoring and reporting restrictions, the base-ten threshold effect that we document is most likely a lower bound to the prevalence of this phenomenon for revenue numbers throughout the economy.

The next section reviews related literature and develops our hypotheses. Section III describes the sample and research design. Section IV presents the empirical results. We provide a summary and conclusion in Section V.

\section{Background and Hypothesis Development}

Humans find base-ten reference points of the form $\mathrm{N} \times 10^{\mathrm{K}}$ easy to use and easy to remember. Studies that require participants to generate numbers have found a strong tendency of respondents to produce round numbers in a significantly higher frequency than would be expected by chance (Turner 1958; Higgins et al. 1977; Huttenlocher et al. 1990; Tarrant and Manfredo 1993; Whynes et al. 2005).

Additionally, several studies in the cognitive accessibility literature find evidence that consumers perceive numbers just below round numbers, for example $\$ 29.99$, to be significantly smaller than the round number above, $\$ 30.00$ (Gabor and Granger 1964; Schindler and Kirby 1997). These findings are consistent with research in marketing that demonstrates that consumers view prices ending in 99 cents to be abnormally lower than prices just one cent above (Brenner and Brenner 1982). There are several explanations offered in the literature for these findings. The 
"perceived gain" effect suggests that consumers frame 9-ending prices as round number prices and a small "gain," and prices just above a round number as the round number and a small "loss." Because consumers view losses very unfavorably, they strongly prefer to avoid those "losses" and are attracted to 9-ending prices (Kahneman and Tversky 1979; Schindler and Kirby 1997). In addition, the "truncation" effect suggests that consumers may fixate on the left-most digit when comparing prices and therefore underestimate 9-ending compared to 0 -ending prices (Hinrichs et al. 1982; Poltrock et al. 1984). Lastly, the "image" effect suggests that consumers view 9-ending prices as conveying a sale or bargain and 0 -ending prices as conveying quality (Stiving and Winer 1997; Bizer and Schindler 2005).

A large body of work in finance has documented that some types of psychological biases may affect financial decision making. ${ }^{1}$ If investors are susceptible to a cognitive bias associated with base-ten numbers in reported accounting data, then a likely place to observe that bias is in reported revenue and earnings because managers may anticipate that bias. A vast literature in accounting demonstrates that managers manage earnings to reach a variety of targets at which a perceived benefit is gained (Healy 1985; Burgstahler and Dichev 1997, Dichev and Skinner 2002, Bartov et al. 2002, Abarbanell and Lehavy 2003, Dyreng et al. 2012). We believe it is interesting to specifically focus on thresholds in revenue for several reasons. After earnings, revenue is the most commonly monitored financial performance metric. Revenues have long been known to have incremental information content beyond earnings and are of great interest to investors (Swaminathan and Weintrop 1991). In addition, after earnings, revenues are the accounting number most widely followed by analysts (Rees and Sivaramakrishnan 2007).

\footnotetext{
${ }^{1}$ Models in behavioral finance have examined overconfidence with individuals overestimating the precision of their information signal (Daniel et al. 1998; Kyle and Wang 1997; Odean 1998), limited attention with individuals neglecting an information signal (Hirshleifer and Teoh 2003; Peng and Xiang 2006), and cumulative prospect theory with individuals overestimating the likelihood of rare events (Barberis and Huang 2008).
} 
Finally, as discussed in Stubben (2010), focusing on one component of earnings decreases noise and increases the power of tests to detect manipulation. This is especially the case in our setting where identifying potential manipulation in reported revenue to reach specific revenue targets casts light on the quality of earnings that would not be apparent by looking only at the distribution of earnings.

Several papers in accounting have been motivated by the cognitive reference point literature in psychology. Carslaw (1988) finds, for a sample of New Zealand firms, more zeros and fewer nines in the second digit of reported earnings than would be expected by chance, implying that at least some firms are stretching themselves to move from reported earnings of, say, $\$ 99$ or $\$ 999$ to $\$ 100$ or $\$ 1,000$, respectively. Thomas (1989) finds a similar pattern in reported earnings and EPS numbers for U.S. firms reporting profits, with the opposite result for firms reporting losses; firms are more likely to report losses ending in nines (a loss of \$99) and less likely to report losses ending in zeros (a loss of \$100). Das and Zhang (2003) provide evidence that firms tend to report earnings that will allow them to round up EPS to the nearest cent, and firms are more likely to round up when doing so will allow them to meet an external benchmark such as analyst forecasts. Finally, Bamber et al. (2010) find that managers are much more likely to issue 0 - and 5-cent-ending forecasts of EPS than would be expected by chance and that these forecasts are less accurate and overly optimistic. ${ }^{2}$ Overall, these studies indicate the presence of cognitive reference points at base-ten thresholds for reported earnings numbers and provide motivation for our investigation of revenues.

\footnotetext{
${ }^{2}$ This result has a striking resemblance to completely unrelated work in medical research on self-reported body weights (Rowland, 1990; Visscher et al. 2006). Individuals display an end-digit preference for " 0 " and " 5 " when self-reporting weight, and this practice is related to underreporting of actual body weight.
} 
Rational managers are likely to be aware of this cognitive bias in terms of accounting numbers and base-ten thresholds and may exploit the bias. For example, there may be valuation implications for reaching a base-ten reference point. Thomas (1989) argues that if the \$1.99 phenomenon accurately describes investor behavior, then a small change in reported accounting numbers may have a disproportionately large effect on firm valuation.

Pervasive numerical cognitive bias may lead to an increase in visibility for firms reporting accounting numbers just above a base-ten threshold number. Appendix 1 contains five examples (Starbucks, 1997; Callaway Golf, 2007; Heinz, 2008; Facebook, 2012; and the U.S. federal government, 2015) illustrating the emphasis base-ten thresholds are given in the press. Firms that report accounting numbers that meet or just beat a base-ten threshold may be more likely to capture the attention of investors and the financial press. This increase in attention may lead to a net increase in buying by individual investors and a net increase in coverage by the media. Odean (1998) proposes that investors limit their choice of stocks to those that have caught their attention because there are limits to how much information these individual investors can process in their search for stocks. Therefore, investors will be more likely to purchase stocks that have recently caught their attention. Barber and Odean (2008) provide evidence consistent with this "attention-grabbing" hypothesis and find that stocks that receive more attention in the financial press are more likely to be purchased by individual investors. ${ }^{3}$

\footnotetext{
${ }^{3}$ It can be argued that investors confront the same problem when selling stocks. However, most investors own a very small subset of available common stocks in their portfolio. Barber and Odean (2008) report that in their large brokerage dataset, the mean household held 4.3 stocks and the median household held 2.6 stocks. In addition, most individual investors do not short-sell stocks. This indicates that these investors will be able to take the time needed in considering whether or not to sell each stock in their portfolio. This leads to the argument that attention is a factor that influences the stocks that individual investors buy, but does not influence the stocks that individual investors sell.
} 
In addition, this cognitive bias with respect to base-ten reference points may permeate both contracts and quasi-contracts. If a cognitive bias increases the likelihood that contracts (such as loan agreements and management compensation schemes) and quasi-contracts (such as analyst and management forecasts of revenues and earnings) are denominated in round numbers, then managers actively seeking to reach these targets will be more likely to report accounting numbers just above a base-ten threshold than just below. Together, these valuation and contracting explanations suggest that rational managers have reasons to prefer reporting earnings and revenue numbers in excess of base-ten thresholds.

For the reasons given above, we predict that managers respond to the preference of market participants for revenues in excess of base-ten thresholds by managing revenues to meet or exceed those thresholds. Although previous studies have shown that firms' reported earnings are more often just above base-ten reference points than would be expected by chance (Carslaw 1988; Thomas 1989), it has not been shown whether this same pattern exists for reported revenue. In addition, because the base-ten threshold revenue effect we predict to find is the result of a human cognition bias focused on numbers, not economic values, it should therefore be independent of the reporting currency. Formally, we predict:

\section{H1: Firms are more likely to report revenues that are just above a base-ten threshold than just below, regardless of the reporting currency.}

We also investigate some of the motives that lead managers to exhibit this base-ten threshold-reaching behavior. Analyst forecasts are a form of quasi-contract, setting a performance expectation for both managers and market participants. As such, managers have an incentive to report numbers that meet these forecast levels. If revenue forecasts exhibit the existence of a base-ten threshold, this is one more reason for the reported revenue numbers 
themselves to exhibit this same threshold effect. It is reasonable to expect this effect in analyst forecasts because financial analysts, like all humans, fixate to some extent on base-ten thresholds. Herrmann and Thomas (2005) document that analysts' forecasts of earnings per share (EPS) end in the digits " 0 " and " 5 " at a much great frequency than do actual EPS. Bamber et al. (2010) document a pattern of "heaping" in their sample of management earnings forecasts. We predict the existence of a similar effect around base-ten thresholds in revenue forecasts.

\section{H2a: Analysts are more likely to issue revenue forecasts that are just above a base-ten threshold than just below.}

Herrmann and Thomas (2005) provide evidence that forecast "heaping" is more likely to come from analysts that are less informed, exert less effort, and have fewer resources, and they suggest that this result is consistent with a behavioral bias. This tendency might be expected to be especially strong in the face of greater uncertainty, necessitating greater use of heuristics, such as base-ten rounding, in making forecasts. Information uncertainty is greater when the forecasting horizon is longer. Accordingly, we make the following prediction.

\section{H2b: The base-ten revenue threshold effect is stronger for revenue forecasts made early in the year than for revenue forecasts made just before the announcement of actual revenue.}

If managers of firms expect a valuation benefit from reaching base-ten revenue thresholds, then we should observe variation in the magnitude of the threshold effect when this expected valuation benefit varies cross-sectionally. In particular, firms with a high sensitivity to revenue news are more likely to benefit from beating these benchmarks. Accordingly, the managers of these firms may be more likely to exert efforts in order to report revenue above a base-ten threshold. We suggest that firms with high price-to-sales ratios or high past revenue growth are particularly sensitive to revenue news. These firms are expected by the market to 
have especially high future revenue growth, and thus the potential stock price penalty to them of not reaching a seemingly-attainable base-ten threshold will be greater than for other firms. We predict the following.

\section{H3a: The base-ten revenue threshold effect is greater for those firms with a higher price-to- sales ratio.}

\section{H3b: The base-ten revenue threshold effect is greater for those firms with higher past revenue growth.}

Market participants susceptible to a cognitive bias associated with base-ten threshold numbers may pay more attention to firms reporting revenue above a threshold. Because this increased public visibility can have a positive valuation effect, as mentioned above, it is rational for managers to engage in efforts to manage reported revenue to exceed base-ten thresholds. We predict that firms that reach a base-ten threshold in reported revenue will experience an increase in visibility manifested by an increase in coverage in the financial media. Formally,

\section{H4: $\quad$ Firms reporting revenues just above a base-ten threshold will experience a greater increase in news coverage relative to a set of control firms.}

Lastly, a firm reporting revenue just above a base-ten threshold is potentially more likely than an average firm to have engaged in unsustainable efforts or revenue management in order to get the visibility and valuation benefits described above. An extensive literature in accounting documents managers achieving earnings and revenue targets through "real" and "accruals-based" earnings management (see e.g., Jones 1991, Roychowdhury 2006, Stubben 2010, Zang 2012). Identifying which particular method, or mix of methods, managers might utilize to achieve a base-ten threshold in a particular case is beyond the scope of this paper. However, we do posit that stretching to reach a base-ten revenue threshold (whether through accruals or through unmaintainable effort or sales practices) represents reported revenue growth that is, in part, 
artificial and therefore unsustainable. Accordingly, we predict that revenue growth for thresholdexceeding firms will be lower, relative to a benchmark set of firms, in the following year.

\section{H5: Firms reporting revenues just above a base-ten threshold will report lower revenue growth in the following year relative to a control set of firms.}

\section{Sample and Research Design}

\section{Sample Selection}

Our initial sample is the entire population of Compustat and Osiris firms for all years 1950 through 2014 for Compustat and 1982 through 2014 for Osiris. We primarily focus on U.S. firms and begin with all Compustat firm-years for which the total asset value is non-missing and positive; this yields 363,905 firm-years. We then delete firm-years with negative or missing values of total revenue, leaving a sample of 350,945 firm-years. Our tests focus on revenue observations just below and just above base-ten thresholds, but we use all of the available data to generate the approximate randomization test statistics based on the empirical distribution of revenue observations just below and just above randomly-chosen revenue thresholds. ${ }^{4}$ The number of firm-years, by decade and by data source, is given in Table 1 .

\section{[Insert Table 1 Here]}

\section{Research Design}

In order to determine whether there are an unexpectedly large number of firms with total revenue just above base-ten thresholds, we use approximate randomization techniques which rely on the properties of randomly-generated distributions as discussed in Noreen (1989). Other

\footnotetext{
${ }^{4}$ The tails of the revenue distribution have only a small number of observations which fall in any given range of potential revenue values. These sparsely populated regions lead to wide variation in the ratio of observations in the regions just above/below the potential comparison thresholds that we use in our approximate randomization procedures (described below). In Appendix 2 we describe how we discard the tails of the distribution by requiring a minimum number of observations in all intervals of a certain width; an almost equivalent procedure would be to simply truncate the extreme tails at the $1 \%$ and $99 \%$ levels. Our results are insensitive to this alternative procedure.
} 
papers in the accounting literature, including Dichev and Skinner (2002), have used similar methods. In summary, our method involves calculating the ratio of the number of observations in the interval (or "bin") just above base-ten thresholds to the number of observations in the bin just below and then comparing this above/below ratio to the value of ratios for a set of pseudothresholds generated from the empirical distribution using random sampling techniques. An above/below ratio around base-ten thresholds that is significantly larger than the ratios around other points along the number line is evidence that firms manage their revenues to be just above these benchmarks. In later tests, we also extend this method using a ratio-of-ratios approach which allows us to compare the magnitude of the base-ten threshold effect in revenues with various other benchmarks such as cost of goods sold and total assets.

For convenience, we transform the revenue data by computing the base-ten logarithm of each revenue number. This transformation results in a revenue distribution that is approximately normal (although a normal distribution is not necessary for our methodology) and, most importantly, results in a natural scaling of the data because the width of bins can be interpreted in terms of percentage changes instead of absolute changes. Prior literature has discussed the need to scale when examining discontinuities in earnings distributions (see Burgstahler and Dichev 1997, Burgstahler and Chuk 2015) because larger firms are able to manage larger absolute amounts near thresholds. The log approach effectively allows the revenue numbers themselves to serve as the scaling variable for the bin widths, avoiding the problems associated with other scalars such as price (see Durtschi and Easton 2005, 2009, and Burgstahler and Chuk 2015). The changes in logged revenue can then easily be converted back to percentage changes in unlogged revenue; for example, a 0.0100 change in logged revenue translates to a change of $2.33 \%$. 
We identify 53 potential threshold points that we expect to be salient to managers, investors, and other market participants. The potential threshold points range from $\$ 100,000$ to $\$ 80$ billion; we do not examine potential thresholds outside this range because very few firms covered by Compustat report revenue values larger or smaller than this. Each order of magnitude $\left(10^{5}, 10^{6}\right.$, through $\left.10^{9}\right)$ includes nine intermediate threshold points such as $\$ 100,000, \$ 200,000$, $\$ 300,000$, up through $\$ 900,000$; the final order of magnitude, $10^{10}$, includes only 8 potential threshold points up to $\$ 80$ billion.

In order to identify whether there are significantly more firms with total revenue just above than just below base-ten thresholds, we first assign observations into intervals or bins around each potential threshold point according to the logged value of annual revenue. Around each threshold point we construct two bins, labeled the BELOW bin and the ABOVE bin. If managers perceive there to be some benefit to reporting revenue greater than or equal to a baseten threshold, then we expect a larger number of observations in bins just above base-ten thresholds than in bins just below those same thresholds. To illustrate, consider the case of log 0.0100 bin widths and the bins 8.9900 and 9.0000 . The bin 8.9900 includes all firm-years with reported revenue greater than or equal to $\$ 977,237,221\left(\$ 1 \times 10^{8.9900}\right)$ and less than $\$ 1,000,000,000\left(\$ 1 \times 10^{9.0000}\right)$. An increase in reported revenue from the bottom of the bin $(\$ 977,237,221)$ to the top of the bin $(\$ 1,000,000,000)$ represents a revenue increase of $2.33 \%$. The adjacent bin 9.0000 includes all firm-years with reported revenue greater than or equal to $\$ 1,000,000,000\left(\$ 1 \times 10^{9.0000}\right)$ and less than $\$ 1,023,292,992\left(\$ 1 \times 10^{9.0100}\right)$. Again, an increase in reported revenue from the bottom of the bin to the top of the bin represents a revenue increase of $2.33 \%$. Thus, even though the absolute dollar width of the two bins is different $(\$ 22,762,779$ 
versus $\$ 23,292,992)$, the width of each bin, relative to the bottom threshold of the bin, is the same, $2.33 \% .^{5}$

We report results using several bin widths: $\log 0.0010$ ( $0.23 \%$ of revenue), 0.0025 ( $0.58 \%$ of revenue), 0.0050 ( $1.16 \%$ of revenue), 0.0100 ( $2.33 \%$ of revenue), $0.0200(4.71 \%$ of revenue), 0.0250 (5.93\% of revenue), 0.0400 (9.65\% of revenue), 0.0500 (12.20\% of revenue), 0.0750 (18.85\% of revenue), and 0.1000 (25.89\% of revenue). As demonstrated later, considering which bin widths display significant results can give some indication of the magnitude of the flexibility firms have, on average, to reach base-ten threshold points.

We compute the test statistic, $S_{j}$, by summing the number of observations in the bins just above all base-ten thresholds, the ABOVE bins, and dividing by the sum of the number of observations in the bins just below all base-ten thresholds, the BELOW bins. The subscript $j$ denotes the various bin widths, from $\log 0.0010$ up through $\log 0.1000$. If managers try to increase revenue to be above base-ten thresholds, we would expect the $S_{j}$ ratio to be greater than 1.

$$
S_{j}=\frac{\sum_{i=1}^{W j} A_{i}}{\sum_{i=1}^{W j} B_{i}}
$$

where $\mathrm{i}=1, \ldots, \mathrm{W}_{\mathrm{j}}$ are the base-ten threshold points, $\mathrm{W}_{\mathrm{j}}$ is the number of threshold points for a given bin width $\mathrm{j}$, up to a maximum of 53 , and $A_{i}$ and $B_{i}$ represent the number of observations in the ABOVE and BELOW bins within width $\mathrm{j}$ of threshold i, respectively. ${ }^{6}$

\footnotetext{
${ }^{5}$ Defining the bin widths to be equal in percentage terms implies that the upper bin for a given revenue number is always larger, in absolute terms, than the lower bin. In untabulated results, we also perform our analysis with ABOVE and BELOW bins for each threshold point constrained to be equal in absolute terms; there is no change in our inferences. The empirical distributions generated in our approximate randomization tests (described later) naturally control for this difference in absolute size of the BELOW and ABOVE bins.

${ }^{6}$ There is a maximum value of 53 base-ten thresholds, but many of the tests do not include all of the potential baseten thresholds because of sample size restrictions detailed in Appendix 2. For example, the log 0.0010 bin-width results reported in Table 2 include only 43 of the 53 thresholds, while the wider 0.0250 bin width allows for the
} 
We use an approximate randomization test to determine whether the $S_{j}$ ratio is significantly greater than one. We generate pseudo values of $S_{j}, \hat{S}_{j}$, by randomly selecting $\mathrm{W}_{\mathrm{j}}$ pseudo threshold points without replacement from the entire set of reported revenue numbers and then counting the number of observations in the ABOVE and BELOW bins relative to these pseudo threshold points. We repeat this process 9,999 times and count the number of times, $r$, that the randomly-generated pseudo-statistic $\hat{S}_{j}$ is greater than or equal to the originallycomputed value of $S_{j}$. Following Noreen (1989), the approximate randomization p-value is computed as follows:

$$
P\left(S_{j}\right)=\frac{r+1}{9,999+1}
$$

where $r=\sum_{j=1}^{9,999} I\left(\hat{S}_{j} \geq S_{j}\right)$, I is the indicator function, and $\mathrm{j}$ is the bin width. We repeat this procedure for each different bin width, $\mathrm{j}$, from $\log 0.0010$ ( $0.23 \%$ of revenue) through $\log 0.1000$ ( $25.9 \%$ of revenue). For example, assume that the actual value of $S_{j}$ is 1.20 and that of the 9,999 randomly-selected sets of bins, none resulted in a pseudo-statistic $\hat{S}_{j}$ value as large as 1.20 . In this case, the value of $\mathrm{P}\left(\mathrm{S}_{\mathrm{j}}\right)$ is $0.0001=((0+1) /(9,999+1))$. This test thus allows us to estimate the significance of the base-ten threshold effect, using randomly-chosen points in the empirical distribution as the benchmark group.

In their work on base-ten thresholds in net income, Carslaw (1988) and Thomas (1989) use a methodology of looking at deviations of second digits from their expected frequencies, based on Benford's Law. ${ }^{7}$ By examining the distribution of observations throughout the range of possible values, instead of just the distribution of second digits, the approximate randomization

examination of all 53 potential thresholds. This variation in the number of thresholds examined occurs because narrow bins are more likely to include few or no observations at the extreme tails of the distribution of observations.

${ }^{7}$ Benford's Law is an empirical regularity whereby certain digits are more likely to occur in the leading positions of numbers in naturally-generated data; Benford's Law is discussed further in Section IV. 
technique that we use essentially sidesteps issues related to Benford's Law while controlling for the actual empirical distribution of accounting numbers. The benefit of this technique is that we are not required to make any assumptions about the statistical properties of the reported revenue distribution. Also, the approximate randomization technique allows us to examine the magnitude of the flexibility firms have to stretch reported revenue to reach a threshold because we can precisely vary the size of the interval (bin) above and below the thresholds that we examine. The second-digits methodology employed by Carslaw and Thomas is constrained to examine nonadjustable bin widths of varying relative sizes. For example, the relative size of any revenue management activity to move a firm from $\$ 990,000$ in revenue to $\$ 1,000,000$ in revenue is much smaller $(1.01 \%)$ than to move a firm from $\$ 1,900,000$ in revenue to $\$ 2,000,000$ in revenue $(5.26 \%)$, and yet both these two cases are treated the same with the second-digits methodology. Finally, as discussed below, our approach makes it easy to directly compare the threshold effect across two sets of firms or reported numbers.

\section{Empirical Results}

As an initial illustration of the components of the $\mathrm{Sj}$ statistics for the set of base-ten thresholds, Table 2 contains the total number of firm-year observations falling in the ABOVE and BELOW bins for base-ten revenue thresholds using log 0.0010 bin widths on either side of the thresholds. For each threshold, we also include a binomial probability as an initial measure of the significance of the effect at each base-ten threshold point. If the distribution of logged revenue observations is uniform, then the number of observations in adjacent bins should be equal; in other words, using any revenue observation as the midpoint for the construction of bins, the probability of other revenue observations that fall in either the BELOW or ABOVE bin being 
in the ABOVE bin is $50 \%$. Although the overall revenue distribution is clearly not uniformly distributed, small intervals in a smooth distribution are likely to be approximately uniform. We check the reasonableness of this assumption by computing the probability of nearby observations (within log 0.0010 below and above) falling in the ABOVE bin for all of the intervals within the full range of revenue observations. For the entire sample, this probability is 50.4\%. For observations below the median value of $\$ 75.9$ million, the ABOVE probability is $50.9 \%$; for observations above the median value of $\$ 75.9$ million, the probability is $49.8 \%$. This difference reflects the increasing then decreasing frequency of observations in a normal distribution. Overall, the 50\% assumption underlying the binomial test provides a reasonable basis for initial measures of statistical significance; however, subsequent tests use the empirical distribution of the observations to create a more precise test statistic.

\section{[Insert Table 2 Here]}

The results in Table 2, Panel A indicate that, for all base-ten threshold levels, there are more reported revenue observations in the $\log 0.0010$ bin just above the threshold than in the bin just below the threshold. ${ }^{8}$ For example, there are 148 firm-year revenue observations in the bin 7.0000 [greater than or equal to $\$ 10,000,000\left(\$ 1 \times 10^{7.0000}\right)$ and less than $\$ 10,023,052(\$ 1 \times$ $\left.10^{7.0010}\right)$ ] compared to just 66 firm-year revenue observations in the bin 6.9990 [greater than or equal to $\$ 9,977,001\left(\$ 1 \times 10^{6.9990}\right)$ and less than $\left.\$ 10,000,000\left(\$ 1 \times 10^{7.0000}\right)\right]$. For all base-ten thresholds, the value of $S_{0.0010}$, the ratio of the number of ABOVE observations to BELOW observations, is 1.55 . Panel B contains results for only the most prominent subset of base-ten

\footnotetext{
${ }^{8}$ Table 2 includes only 43 of the 53 possible thresholds that we examine in this study because the 0.0010 bin width, unlike wider bin widths, is too narrow to include enough observations to meet our minimum observation criterion for values at the tails of the distribution. Our minimum observation criterion is explained in detail in Appendix 2.
} 
thresholds: \$1 million, \$10 million, \$100 million, and \$1 billion, and \$10 billion. For this subset, the ABOVE/BELOW ratio is 1.87 and the binomial p-value is highly significant $(<0.001)$.

Underlying the simple binomial test is the assumption that each observation is independent. This condition is satisfied for the small bin widths, but the large bin widths have overlapping regions, and observations in the ABOVE bin for one threshold point can be in the BELOW bin for another threshold point. For example, consider the largest bin width $\log 0.1000$, or $25.89 \%$ of revenue. A revenue observation of $\$ 990,000$ is clearly in the BELOW bin for the $\$ 1,000,000$ threshold point, but it is also in the ABOVE bins for the $\$ 800,000$ and $\$ 900,000$ threshold points. The approximate randomization test described earlier does not require the assumption of independent observations. In Table 3 we provide p-values generated by the approximate randomization procedure for the full set of combined thresholds. These statistics allow us to estimate the combined significance of the threshold effect across all of the thresholds reported individually in Table 2 using an unbiased test statistic.

In Table 3, Panel A we report values of $S_{j}$, the ratio of the number of revenue observations in the bin just above a threshold point to the number of observations in the bin just below that same threshold point for a variety of bin widths around the thresholds. Consistent with the results in Table 2 for just the 0.0010 bin width, the number of ABOVE observations exceeds the number of BELOW observations for all bin widths. For each bin width, we report a binomial probability that we would observe that many observations in the ABOVE bins relative to the BELOW bins if the true underlying probability of an observation falling in one of the bins is $50 \%$. The binomial p-values are less than 0.01 for all bin widths, indicating that it is very unlikely that this would occur by random chance. As seen in the far right column of Table 3 , Panel A, the approximate randomization p-values agree with the binomial p-values for the small 
bin widths, but for the large bin widths, particularly $25.89 \%$ in which there are many observations counted more than once, the approximate randomization results demonstrate that the simple binomial test overstates the statistical significance of the ABOVE/BELOW ratio. With that said, for all bin widths from $\log 0.0010(0.23 \%$ of revenue) through $\log 0.0500$ (12.20\% of revenue), the approximate randomization p-values are less than 0.01 demonstrating that there are significantly more reported revenue numbers just above a base-ten threshold than just below a base-ten threshold, supporting our hypothesis that managers manage reported revenues to reach these base-ten benchmarks.

\section{[Insert Table 3 here]}

One issue to consider with respect to the test statistics in Panel A is that the observation counts in the ABOVE and BELOW bins for the different bin widths are cumulative, meaning that if an observation is in the ABOVE bin for the $0.23 \%$ bin width in Table 3 , Panel A, that same observation is also in the ABOVE bin for the $25.89 \%$ bin width. Part, or all, of the significant difference in the ABOVE/BELOW number of observations for the larger bin widths could therefore be the result of the differences for the smaller bin widths. This is analogous to a significant five-day abnormal market return being the result of four days of zero abnormal returns and one day with a large abnormal return. Intuitively, it seems unrealistic that firms would be able and desirous to manage revenues to increase them by $9.65 \%$ or $12.20 \%$ (two of the significant bin widths in Table 3, Panel A) in order to reach a base-ten revenue threshold.

To explore this issue, we tabulate observations in incremental revenue bands, as shown in Table 3, Panel B. For example, we see in Panel A that there are 32,475 observations in the ABOVE bins within $2.33 \%$ of a base-ten threshold. However, only 15,692 of these observations are in the band close to the upper limit of $2.33 \%$, in the band between $1.16 \%$ and $2.33 \%$ above a 
base-ten threshold point. We use these incremental observation counts (i.e. observations in the current bin width that were not included in the next smallest bin) to generate new ratios and associated approximate randomization p-values. The incremental p-values of only the four smallest bins are significant at the $5 \%$ level. ${ }^{9}$ These incremental results suggest that firms are desirous and able to manage revenues within about a $2.33 \%$ range to reach base-ten threshold points. The statistical significance for wider bins results from the holdover effect from the ABOVE/BELOW difference for the narrower bins. In subsequent tables, we focus on reporting results just for this set of narrower bins. ${ }^{10}$

The results reported in Tables 2 and 3 are interesting but still have the potential to be driven to some extent by less opportunistic reasons than managers' desire to beat base-ten cognitive thresholds. For example, additional rounding of revenue numbers could have been introduced by the data-provider when aggregating the revenue data. Alternatively, managers might have a tendency to subconsciously round up all reported accounting numbers because of the appealing properties of round numbers discussed earlier. In that case, managers would not consciously be targeting base-ten revenue thresholds specifically, and would be just as likely to round up numbers that are not usually subject to upwards management such as cost of goods sold. Finally, prior studies examining base-ten thresholds for reported earnings numbers have identified these irregularities by examining the distribution of the digits in reported numbers. A digits-based methodology must take into account Benford's Law, which demonstrates that digits in naturally-occurring numbers are not uniformly distributed and that numbers with a second

\footnotetext{
${ }^{9}$ Note that the incremental p-value in Panel B for 0.0010 is the same as in Panel A because it is the smallest bin width and therefore is essentially only incremental to a bin width of 0 .

${ }^{10}$ The total number of observations used in Panel B is slightly lower than the number used in Panel A because of our minimum observation restrictions (309,369 vs. 309,411 and 311,539 vs. 311,745 in the lower and upper bins, respectively). By looking at incremental bin widths, we are essentially looking at sets of much smaller bins which are more likely to include too few observations to be included in the statistical analysis.
} 
digit of 0 (e.g., 500) are more likely to occur than numbers with a second digit of 9 (e.g., 490). ${ }^{11}$ However, Benford's Law most accurately describes sets of numbers that span several orders of magnitude and does not describe the distribution of numbers at adjacent points on the number line. In other words, Benford's Law does not imply any sort of discontinuity in the distribution of numbers, and is a less likely explanation for our results.

To rule out all three of the above possible mechanisms as the cause of our results in Tables 2 and 3, we compare the ABOVE/BELOW ratios for the revenue thresholds with those for cost of goods sold, total assets, and market capitalization. We label these comparisons "ratioof-ratios tests" because we compare the $S_{\mathrm{j}}$ statistics (aggregate threshold ABOVE/BELOW ratio) for revenue with the $S_{j}$ statistics of the other metrics. Finding elevated ABOVE/BELOW ratios in revenue data beyond those in these other three data items would suggest that managers are motivated to take actions to increase revenue to reach these base-ten revenue thresholds above and beyond any intentional or unintentional behavior on the part of managers to manage these other numbers. We choose these three data items as controls because total assets, market capitalization, and cost of goods sold are all, on average, of the same order of magnitude as revenue. Cost of goods sold is a particularly apt benchmark because it is generated by similar processes that lead to revenues, has a similar distribution in terms of magnitude, and is much less likely to be strategically managed to exceed base-ten thresholds. Because managers could

\footnotetext{
${ }^{11}$ Casual intuition suggests that each of the nine digits 1 through 9 is equally likely to appear as the first digit in a reported revenue number and that each of the ten digits 0 through 9 is equally likely to appear as the second digit, but this is not the case. For example, according to Benford's Law, in a set of numerical data, the first digit will be "1" $30.1 \%$ of the time and will be "9" only $4.6 \%$ of the time. For numbers of two digits or more, the second digit will be " 0 " $12.0 \%$ of the time and "9" only $8.5 \%$ of the time. Benford's Law arises naturally out of any exponential growth process. Benford's Law also emerges naturally for any data set in which the observed values are randomly drawn from different distributions, and this phenomenon has been shown to be true in accounting data (Nigrini 1996; Nigrini and Mittermaier 1997). Amiram et al. (2015) use deviations from Benford's Law to calculate a measure of financial statement data quality and predict material misstatements.
} 
potentially have incentives to manipulate upward both total assets and total market value of equity, these benchmarks place an even higher bar for the magnitude of the base-ten threshold effect in revenues in order to find significant results. ${ }^{12}$

Using cost of goods sold as an illustration, the test statistic, $\mathrm{V}_{\mathrm{j}}$, for these ratio-of-ratios tests is the ratio of the separate $S_{j}$ statistics for revenue and cost of goods sold.

$$
V_{j}=\frac{S_{j, \text { Revenue }}}{S_{j, \text { COGS }}}
$$

where $S_{j, \text { Revenue }}$ is the ratio of the number of ABOVE and BELOW observations in bin width $j$ around all base-ten thresholds for revenue and $\mathrm{S}_{\mathrm{j}, \mathrm{COGS}}$ is the same ratio for cost of goods sold. If managers have incentives to manage reported revenue to exceed base-ten thresholds above and beyond any threshold effect that may exist for cost of goods sold, then this $V_{j}$ ratio should be greater than one. A similar ratio-of-ratios test statistic is computed using total assets and market capitalization.

We use a similar approximate randomization test as described earlier to determine whether the $\mathrm{V}_{\mathrm{j}}$ ratio is significantly greater than one, now randomly selecting points from both the revenue and comparison metric distributions. Data comparing the magnitude of the base-ten threshold effect in reported revenue numbers to the corresponding effect in cost of goods sold, total assets, and market value of equity are presented in Table 4. The data in Panel A relate to base-ten thresholds in cost of goods sold. For each bin width, the ratio of ABOVE-to-BELOW cost of goods sold observations is greater than one, indicating that some amount of innocuous rounding by the firm or data provider is occurring, even for cost of goods sold.

\footnotetext{
${ }^{12}$ Although firms have more difficulty in directly managing ending market capitalization for an accounting reporting period than in managing reported revenues or assets, evidence such as in Iliev (2010) suggests that firms can exercise some influence on the level of end-of-period market values (in his case he examines public float).
} 


\section{[Insert Table 4 here]}

The excess of ABOVE-to-BELOW observations for cost of goods sold provides a benchmark for the magnitude of the threshold-reaching effect in the revenue numbers. The ratioof-ratios analysis shown in Table 4, Panel A demonstrates that for each of the bin widths reported, there is a significantly greater proportion of revenue observations, relative to cost of goods sold observations, just above a base-ten threshold; the approximate randomization p-value reported in the final column is less than 0.01 in each case. This ratio-of-ratios value is as high as 1.430 for the $0.23 \%$ bin width. These results reconfirm that there is strong evidence that managers of firms with revenues close to a base-ten threshold make extra efforts to reach that threshold.

In Table 4, Panels B and C, we report ratio-of-ratios comparisons for revenues with both total assets and market value of equity. As with the cost of goods sold comparison, the ratio of the number of observations falling in bins just above a base-ten threshold, relative to the number of observations just below that base-ten threshold, is significantly higher than for total assets (Panel B) and market value of equity (Panel C). Taken together, the results reported in Table 4 strongly support our prediction that firms are more likely to take strategic action to report revenues that are just above a base-ten threshold than just below.

Our prediction about base-ten threshold-reaching behavior is based on the nature of the reported numbers themselves and not on the underlying economic values. We predict the same effect to be evident in numbers reported in any currency. Accordingly, we repeat the ratio-ofratios analysis on international data to demonstrate the robustness of the base-ten revenue threshold effect and to show that this effect is not unique to the U.S. market or to U.S. dollars. The international results are shown in Table 5, Panels A and B. Two sets of results are given - 
results for all base-ten threshold points (in Panel A) and results for just the six most prominent threshold points (in Panel B). Because the numerical nature of the hypothesized base-ten threshold effect is independent of any currency denomination, it is appropriate in this case to pool unadjusted revenue numbers across countries and currencies. In total, the results in Table 5 represent revenue and cost of goods sold data from 140 different non-U.S. countries and 107 different currencies. ${ }^{13}$

\section{[Insert Table 5 here]}

We use 390,104 revenue observations from Bureau van Dijk’s Osiris database. We use Osiris because it covers the greatest number of countries of any international accounting database (Dai 2012); although less commonly used in accounting research, it has been used in a variety of studies in finance (see John et al. 2008; Masulis et al. 2011). The approximate randomization p-values associated with the ratio-of-ratios tests for the Osiris data are all less than 0.05 (less than 0.01 in most cases) and demonstrate that for all of the bin widths examined, using both the full set of thresholds (Panel A) and the most prominent thresholds (Panel B), managers in non-U.S. firms make efforts to increase reported revenue to reach base-ten thresholds. This result is quite striking because it has nothing to do with economic value and everything to do with the base-ten fixation of human number processing, in all currencies.

In sum, the results of Tables 2 through 5 provide strong support for our prediction that firms are more likely to report revenues that are just above a base-ten threshold than just below. We show that the effect is significant for revenue numbers within one or two percent of a baseten threshold. Using a ratio-of-ratios test with cost of goods sold, total assets, and market value

\footnotetext{
${ }^{13}$ Although most of the ratios tend to be greater in Panel B, the approximate randomization p-values tend to be smaller in Panel A. This is because all of the less prominent thresholds are included in the control group in Panel B which compares the most prominent thresholds with all other numbers.
} 
of equity as control numbers, we also demonstrate that this base-ten revenue threshold effect is incremental to any effect of non-strategic rounding. Finally, we show that the base-ten revenue threshold effect exists even when aggregating more than 60 years of unadjusted revenue data and when aggregating non-U.S. revenue numbers reported in a variety of currencies. ${ }^{14}$ This base-ten revenue threshold effect is not associated with any measure of economic value in the reported revenue numbers but is instead driven by cognitive fixation on base-ten thresholds.

\section{Analyst Revenue Forecasts}

Analyst forecasts establish a performance expectation for both managers and market participants. If revenue forecasts exhibit the existence of a base-ten threshold, this is one more reason for managers to make efforts to reach base-ten thresholds in reported revenues. We explore the existence of a base-ten threshold effect in analysts' revenue forecasts in Table 6. The underlying data are analyst revenue forecasts obtained from the IBES database for the years 1996 through 2013. We focus on the first forecast as well as the final forecast; the final forecast is the one made closest to the announcement of actual revenue.

\section{[Insert Table 6 here]}

The results in Table 6, Panels A and B confirm that a base-ten threshold effect exists in analysts' annual revenue forecasts. In both panels a ratio-of-ratios test is employed. Panel A contains results for the first forecast, compared to actual cost of goods sold, and Panel B contains results for the final forecast, also compared to actual cost of goods sold. For both the first revenue forecast and the final revenue forecast, for each of the four bin widths reported, the approximate randomization test reveals the existence of a strongly significant base-ten threshold effect. These

\footnotetext{
${ }^{14}$ Although our tests include data from as early as the 1950s, this base-ten revenue threshold phenomenon persists today and can be observed in the data even when restricting the sample to include only those firm-years occurring after the year 2000 .
} 
results confirm that not only does the base-ten threshold effect exist in actual reported revenue, but it also exists in analysts' forecasts of revenue.

Table 6, Panel $\mathrm{C}$ reports the results of a ratio-of-ratios comparison between the first revenue forecast and the final revenue forecast allowing us to compare the strength of the revenue threshold effect in analyst forecasts issued closer to and further from the earnings announcement date. For the three narrowest bin widths, the approximate randomization test confirms that the base-ten threshold effect is significantly stronger in the first revenue forecast relative to the final forecast. Consistent with $\mathrm{H} 2 \mathrm{~b}$, the fact that the base-ten threshold effect is stronger in earlier forecasts suggests that analysts are more likely to fixate on a base-ten heuristic when faced with greater uncertainty early in the forecasting period when they have less information about actual firm performance during the period.

Table 6, Panels D and E report the results of a ratio-of-ratios comparison between actual reported revenue and the first and last revenue forecast, respectively. The Panel D results demonstrate that the base-ten threshold effect is significantly stronger in the early analysts' revenue forecasts than in the actual reported revenues; the approximate randomization $\mathrm{p}$-value is significant for each of the four reported bin widths. Interestingly, the Panel E results reveal that the base-ten threshold effect in the last analyst forecasts exhibits the base-ten threshold effect to about the same degree as seen in the actual revenue numbers; the approximate randomization tests shows that the ratio of threshold ratios $\left(\mathrm{V}_{\mathrm{j}}\right)$ is indistinguishable from one for each of the four bin widths. These results in Panel E suggest that part of the reason that firms meet base-ten thresholds in reported revenue is that managers are trying to meet analyst revenue forecasts which exhibit base-ten threshold effects. Overall, these results provide support for $\mathrm{H} 2 \mathrm{a}$ and $\mathrm{H} 2 \mathrm{~b}$. 


\section{Revenue Sensitivity}

We suggest that because there is greater attention to reported revenue for high price-tosales and high past revenue growth firms, these firms should benefit the most from meeting baseten revenue thresholds. Accordingly, $\mathrm{H} 3 \mathrm{a}$ and $\mathrm{H} 3 \mathrm{~b}$ predict that the base-ten revenue threshold effect is stronger among high price-to-sales ratio and high past revenue growth firms. In Table 7 , Panels $\mathrm{A}$ and $\mathrm{B}$, we report results examining the relation of the base-ten threshold effect with past revenue growth and price-to-sales ratios, respectively. We define revenue growth as the percentage change in revenue from year $\mathrm{t}-1$ to $\mathrm{t}$ (where $\mathrm{t}$ is the current year). Because this measure is correlated with current revenue, we use lagged values to sort firms into revenue growth deciles. Before constructing deciles, we exclude the extreme high and low $2 \%$ of the past revenue growth firm-years for the Panel A results and the price-to-sales ratio firm-years for the Panel B results to avoid our results being skewed by extreme positive and negative growth firms.

\section{[Insert Table 7 here]}

In Table 7, Panel A we report the results of the ratio-of-ratios approximate randomization tests comparing the high past revenue growth firm-years (the highest revenue growth decile) and low past revenue growth firms (the lowest revenue growth decile). These results indicate that past revenue growth does appear to have a significant effect on the tendency of a firm to attempt to reach the next higher base-ten threshold point. For all three of the narrowest bin widths, the pvalue of the approximate randomization test is less than 0.05 . These results are consistent with the idea that managers in firms with high past revenue growth are more motivated to seek the positive attention stemming from reaching base-ten reference points.

In Table 7, Panel B we report the results of the ratio-of-ratios approximate randomization tests comparing the highest decile of price-to-sales firm-years and the lowest decile of price-to- 
sales ratio firm years. One determinate of price-to-sales ratios is investors' expectation of future revenue growth. Again, for all three of the narrowest bin widths, the p-value of the approximate randomization test is less than 0.10 , with the 0.0010 and 0.0050 bin widths having a p-value less than 0.05 . These results suggest that managers in high price-to-sales firms are more likely to expend the efforts necessary to reach a base-ten revenue threshold, consistent with the revenue threshold effect being strongest for firms which have the greatest incentives to report strong revenue numbers.

\section{Increased Press Coverage}

We suggest that one motivation for rational managers to spend time, money, and effort in reaching base-ten revenue thresholds is that reaching these thresholds results in increased public visibility for the firm. We measure this public visibility by extent of press coverage. To provide evidence that firms experience increased recognition/exposure resulting from reaching a base-ten threshold, for the calendar years 1979 through 2012 we identify a sample of firm-years which have press coverage available in the Factiva database and have just exceeded, by less than $2.33 \%$, the $\$ 1$ billion threshold for the first time. ${ }^{15}$ We compare the press coverage in the threshold year to the press coverage in the prior year. For this test we focus our examination of press coverage in the week surrounding the announcement of $4^{\text {th }}$ quarter earnings. We measure the level of press coverage by querying the Factiva database manually, firm-year by firm-year, for all news outlets covered in Factiva, and tabulating the total number of articles written about the firm in the week surrounding the announcement of annual earnings (three days before, the announcement date, and three days after). We collect the same data for the prior year earnings

\footnotetext{
${ }^{15}$ We focus on the $\$ 1$ billion threshold because news coverage data is not available for many firms with lower levels of revenue and because we anticipate that the strength of the response to this prominent base-ten threshold would give the statistical tests enough power to detect an effect even with the limited sample size.
} 
announcement period. Press coverage for a particular firm-year is defined to be the total number of articles (including duplicates) in this week-long window. We include duplicates because, for our purposes, we are interested in the total volume of press coverage and not in the number of unique press articles. Therefore, if an article originally reported in The New York Times was reprinted in The Kansas City Star, for example, both articles constitute part of the overall press coverage for the firm in question.

The results of this press coverage analysis are reported in Table 8, Panel A. Of the 163 firm-years sampled, 82 have press coverage that was higher in the year they reached the billiondollar benchmark, 29 have the same amount of press coverage, and 52 display a decrease in overall press coverage. For a statistical test of significance, we follow traditional practice (Randles 2001) and ignore the no-change observations. We compare the number of press coverage increase firm-years to the number of decrease firm-years using a binomial test. The number of press coverage increase firm-years is significantly greater, with a p-value of 0.006. These results provide evidence that, on average, firms experience an increase in press coverage in the year that they reach the billion-dollar revenue benchmark.

\section{[Insert Table 8 here]}

A weakness of this press coverage analysis is that we do not control for press coverage changes for similar firm-years that are not associated with the reaching of a base-ten revenue threshold. Accordingly, for our second news coverage test, we use a broader sample and a matched-pair design to provide further evidence of a significant increase in press coverage. For this broader analysis we use automated extraction techniques to download articles for firms with

revenues near both the $\$ 1$ billion and $\$ 500$ million thresholds. This broader firm coverage is 
essential to provide the matched sample for our second news coverage test, but limits our analysis to articles on Factiva originally provided by PR Newswire.

The results of our second news coverage analysis are contained in Table 8, Panel B. We identify 225 firm-years from the period 1990 through 2012 for which reported revenue exceeded either the $\$ 500$ million threshold or the $\$ 1$ billion threshold for the first time and for which we have press coverage data in the current and prior years. The matched sample includes firm-years in the same two-digit SIC code and year with revenue within 50\% of the base-ten threshold and total assets within $50 \%$ of the total assets of the matched firm. We impose the additional restriction that the revenue of firms in the matched sample not cross the base-ten threshold during the two-year period before and after the test firms cross the thresholds of interest for the first time; revenues must be either above or below the threshold for both years. This process identified 898 matching firm-years for the 225 sample firm-years. We define three categories of relative news coverage change, as follows:

- Relative decrease: Threshold firm news coverage decreased while match firm news coverage either stayed the same or increased or threshold firm news coverage stayed the same while match firm news coverage increased.

- No relative change: Threshold firm news coverage and the match firm news coverage both decreased, both stayed the same, or both increased.

- Relative increase: Threshold firm news coverage increased while match firm news coverage either stayed the same or decreased or threshold firm news coverage stayed the same while match firm news coverage decreased.

As seen in Table 8, Panel $\mathrm{B}$, the ratio of the number of relative increases to decreases is 1.14 , with a binomial test p-value of 0.060 , offering support of the claim that surpassing a base- 
ten revenue threshold results in a relative increase in press coverage. We repeat the test using only the closest match below the threshold and the closest match above the threshold. For some sample firm-years, there was not both an appropriate "above" matching firm-year and appropriate "below" matching firm-year, so the total number of matches for this comparison is 306. As seen in Table 8, Panel $\mathrm{B}$, the ratio of relative press coverage increases to decreases is 1.31, and the binomial test p-value is 0.030 . Overall, the results reported in Table 8, Panels A and B provide support for the prediction in $\mathrm{H} 4$ that reaching a base-ten revenue threshold results in a relative increase in press coverage. Accordingly, to the extent that increased visibility brings benefits to a firm, managers are indeed justified in expending efforts to increase reported revenue to exceed an attainable base-ten threshold.

\section{Future Revenue Growth}

H5 predicts that the effort to reach a base-ten revenue threshold is, in part, unsustainable and that future revenue growth for firms reporting revenue just above a base-ten threshold is lower than for a control set of firms. We use the $\$ 1$ billion revenue threshold and identify all firm-years with reported revenue within $2.33 \%$ ( $\log 0.0100)$ below $\$ 1$ billion, and all firm-years within $2.33 \%$ above $\$ 1$ billion. For each observation we also require that revenue data be available for the year before, the year of, and the year after reported revenue is close to the $\$ 1$ billion threshold. This procedure yields 248 firm-years with revenue just below the $\$ 1$ billion threshold and 301 firm-years with revenue just above the $\$ 1$ billion threshold. We compute revenue growth rates in the year that the firm is close to the $\$ 1$ billion threshold and in the year following. The results are reported in Table 9, Panel A. For the firm-years with revenue just below the $\$ 1$ billion threshold, the mean (median) revenue increase in the first year is $10.6 \%$ $(8.4 \%)$, insignificantly different from the mean (median) revenue increase in the following year 
of $9.8 \%(8.7 \%)$. In contrast, for the firm-years with revenue just above the $\$ 1$ billion threshold, the mean (median) revenue increase in the following year of $6.4 \%(6.8 \%)$ is significantly lower than the revenue increase in the year the threshold was reached of $14.5 \%(10.3 \%)$. Note that it was this elevated revenue growth of $14.5 \%$ that allowed these firms to report revenue in excess of the $\$ 1$ billion threshold. These results suggest that some firms stretch to reach base-ten revenue thresholds and that this high revenue growth is not sustainable.

\section{[Insert Table 9 here]}

Table 9, Panel B confirms this unsustainability result using a matched sample design. For the same firm-years examined in Panel A (with revenue within $2.33 \%$ of $\$ 1$ billion), a set of matched firm-years is constructed using firms in the same two-digit SIC code and year with revenue that is within $10 \%$ of the $\$ 1$ billion threshold but which is not within $2.33 \%$ of the threshold. We also require that total assets in the matched firm-years be within $50 \%$ of the total assets of the sample threshold firms. Each near-threshold and match firm pair is categorized based on whether the revenue growth rate increased or decreased in the following year relative to the revenue growth rate from the preceding year. Similar to our news coverage tests, we define three categories of relative revenue growth rate change, as follows:

- Relative decrease: Near-threshold firm revenue growth rate decreased while match firm revenue growth rate increased.

- Same: Near-threshold firm revenue growth rate and the match firm revenue growth rate both decreased or both increased.

- Relative increase: Near-threshold firm revenue growth rate increased while match firm revenue growth rate decreased. 
As seen in Table 9, Panel B, for near-threshold firm-years with revenue just below the $\$ 1$ billion threshold, the ratio of relative revenue growth rate increases to decreases is 1.02 , insignificantly different from one and indicating that for the near-threshold firms that did not stretch to reach the $\$ 1$ billion revenue threshold, revenue growth in the following year was indistinguishable from that of a matched set of firms. For the firm-years with revenue just above the $\$ 1$ billion threshold, the ratio of relative growth rate increases to decreases shrinks dramatically to 0.64 , which is significantly less than one (p-value $<0.01$ ), indicating that revenue growth in the following year was significantly lower among threshold beaters than for a matched set of firms. Overall, the results in Table 9 demonstrate that the revenue growth needed to reach a representative base-ten threshold, $\$ 1$ billion, is not sustainable, on average.

\section{Summary and Conclusions}

Human fixation on base-ten thresholds is likely a consequence of an evolutionary path entered 340 million years ago when the common ancestor of amphibians, reptiles, birds, and mammals evolved to have five digits on each limb (Coates 2005). Humans have two hands and five fingers on each hand, so counting systems around the world are designed around the number 10. Other alternatives (such as base 2 , base 8 , base 12, and base 60) exist, but the base-ten counting system predominates.

In this paper we show that this non-economic base-ten legacy of evolutionary biology has a measurable effect on the actions of managers, financial analysts, news media, and, by implication, the broader set of market participants who respond to the numbers produced by managers and analysts. We find that firms tend to report revenues just meeting or beating baseten thresholds, and this phenomenon occurs in the accounting numbers of firms reporting in a 
variety of countries in a variety of currencies. Although unusual patterns in earnings have been documented in prior research, our paper is the first to document the existence of a base-ten threshold effect in revenues and underscores the importance that managers place on the reported revenue number, independent of its contribution to bottom-line earnings.

Our result is not inconsistent with rational behavior on the part of managers. We find that analyst forecasts of revenues exhibit this effect, and that it is stronger early in the forecasting period when analysts are faced with greater uncertainty, and therefore more likely to rely on heuristics, than later in the forecasting period when they have more information. This suggests that managers may be rationally responding to external incentives to beat these benchmarks. Further, managers of firms for which share prices are most sensitive to changes in market perceptions about future revenues, such as firms with high past revenue growth or with high price-to-sales ratios, are more likely to take actions to reach base-ten thresholds. Additionally, market participants apparently respond to the reaching of these thresholds; we show that press coverage of firms reaching a base-ten threshold increases relative to press coverage of a matched control group of firms. Finally, we find that the efforts needed to push reported revenue above a base-ten threshold are not sustainable; revenue growth in the following year is significantly lower than revenue growth in a matched control sample. Combined, these results are the first to date which provide evidence on both the motives for and intended and unintended consequences of managing accounting numbers to meet base-ten thresholds.

The base-ten revenue threshold effects that we document in this study are exhibited in audited financial statement data. However, it is also likely that this base-ten threshold phenomenon exists in the unaudited financial statements of privately-held businesses which face less scrutiny. Additionally, strategic actions to reach base-ten thresholds are likely to exist in 
internal accounting numbers such as revenue budgets, targets, and internal forecasts. Our results suggest that all reported revenue numbers that just exceed a base-ten threshold by one or two percent may be less reliable than revenue numbers from other points along the number line. Considering the large number of base-ten thresholds present in reported accounting numbers, we believe this has far-reaching implications for the use of these revenue numbers and their associated earnings numbers by academics and practitioners. 


\section{REFERENCES}

Abarbanell, J. and R. Lehavy. 2003. Biased Forecasts or Biased Earnings? The Role of Reported Earnings in Explaining Apparent Bias and Over/Underreaction in Analysts' Earnings Forecasts. Journal of Accounting and Economics 36 (1-3): 105-146.

Albers, W. 2001. Prominence theory as a tool to model boundedly rational decisions. In Bounded Rationality: The Adaptive Toolbox, edited by G. Gigerenzer and R. Selten R, 297-317. Cambridge, MA: MIT Press.

Amiram, D., Z. Bozanic, and E. Rouen. 2015. Financial Statement Errors: Evidence from the Distributional Properties of Financial Statement Numbers. Review of Accounting Studies 20 (4): 1540-1593 .

Bamber, L., K. W. Hui, and E. Yeung. 2010. Managers' EPS Forecasts: Nickeling and Diming the Market? The Accounting Review 85 (1): 63-95.

Barber, B., and T. Odean. 2008. All That Glitters: The Effect of Attention and News on the Buying Behavior of Individual and Institutional Investors. Review of Financial Studies 21 (2): 785-818.

Barberis, N., and M. Huang. 2008. Stocks as Lotteries: The Implications of Probability Weighting for Security Prices. American Economic Review 98 (5): 2066-2100.

Bartov, E., D. Givoly, and C. Hayn. 2002. The Rewards to Meeting or Beating Earnings Expectations. Journal of Accounting and Economics 33 (2): 173-204.

Benford, F. 1938. The Law of Anomalous Numbers. Proceedings of the American Philosophical Society 78 (4): 551-572.

Bizer, G., and R. Schindler. 2005. Direct Evidence of Ending-Digit Drop-Off in Price Information Processing. Psychology and Marketing 22 (10): 771-783.

Brenner, G.A. and R. Brenner. 1982. Memory and Markets, or What Are You Paying $\$ 2.99$ for a Widget? The Journal of Business 55 (1): 147-158.

Burgstahler, D., and E. Chuck. 2015. Do Scaling and Selection Explain Earnings Discontinuities? Journal of Accounting and Economics 60 (1): 168-186.

Burgstahler, D., and I. Dichev. 1997. Earnings Management to Avoid Earnings Decreases and Losses. Journal of Accounting and Economics 24 (1): 99-126.

Carslaw, C. 1988. Anomalies in Income Numbers: Evidence of Goal Oriented Behavior. The Accounting Review 63 (2): 321-327.

Coates, M. 2005. Why do most species have five digits on their hands and feet? Scientific American. April 25, 2005 
Dai, R. 2012. International Accounting Databases on WRDS: Comparative Analysis. Working paper, Wharton Research Data Services. Available at http://wrds-web.wharton.upenn.edu/ wrds/research/applications/guides/pdf/March\%2016\%202012\%20international.pdf.

Daniel, K., D. Hirshleifer, and A. Subrahmanyam. 1998. Investor Psychology and Security Market Under- and Overreactions. Journal of Finance 53 (6): 1839-1885.

Davis, A.K. 2002. The Value Relevance of Revenue for Internet Firms: Does Reporting Grossed-up or Barter Revenue Make a Difference? Journal of Accounting Research 40 (2): 445-477.

Das, S., and H. Zhang. 2003. Rounding-up in reported EPS, behavioral thresholds, and earnings management. Journal of Accounting and Economics 35: 31-50.

Dichev, I., and D. Skinner. 2002. Large-Sample Evidence on the Debt Covenant Hypothesis. Journal of Accounting Research 40 (4): 1091-1123.

Dichev, I.D., J.R. Graham, C.R. Harvey, and S. Rajgopal. 2013. Earnings quality: Evidence from the field. Journal of Accounting and Economics 56 (2-3): 1-33.

Durtschi, C. and P. Easton. 2005. Earnings Management? The Shapes of the Frequency Distributions of Earnings Metrics Are Not Evidence Ipso Facto. Journal of Accounting Research 43 (4): 557-592.

Durtschi, C. and P. Easton. 2009. Earnings Management? Erroneous Inferences Based on Earnings Frequency Distributions. Journal of Accounting Research 47 (5): 1249-1281.

Dyreng, S., W. Mayew, and K. Schipper. 2012. Evidence that Managers Intervene in Financial Reporting to Avoid Working Capital Deficits. Working paper, Duke University.

Editorial Board. 2015. Obama Unchained. Wall Street Journal (February 2): 1.

Gabor, A. and C. Granger. 1964. Price Sensitivity of the Consumer. Journal of Advertising Research 4: 40-44.

----- 1966. Price as an Indicator of Quality: Report on an Enquiry. Economica 33: 43-70.

Ghosh, A., Z. Gu, and P.C. Jain. 2005. Sustained Earnings and Revenue Growth, Earnings Quality, and Earnings Response Coefficients. Review of Accountings Studies 10: 33-57.

Healy, P. M. 1985. The Effect of Bonus Schemes on Accounting Decisions. Journal of Accounting and Economics 7 (1-3): 85-107.

Herrmann, D. and W. Thomas. 2005. Rounding of Analyst Forecasts. The Accounting Review 80 (3): 805-823. 
Higgins, E. T., W. Rholes, and C. Jones. 1977. Category Accessibility and Impression Formation. Journal of Experimental Social Psychology 13: 141-154.

Hinrichs, J., J. Berie, and M. Mosell. 1982. Place information in multidigit number comparison. Memory and Cognition 10 (5): 487-495.

Hirshleifer, D., and S. H. Teoh. 2003. Limited attention, information disclosure, and financial reporting. Journal of Accounting and Economics 36: 337-386.

Huttenlocher, J., L. Hedges, and N. Bradburn. 1990. Reports of elapsed time: Bounding and rounding processes in estimation. Journal of Experimental Psychology: Learnings, Memory, and Cognition 16 (2): 196-213.

Iliev, P. 2010. The Effect of SOX Section 404: Costs, Earnings Quality, and Stock Prices. Journal of Finance 65 (3): 1163-1196.

Jegadeesh, N. and J. Livnat. 2006. Revenues Surprises and Stock Returns. Journal of Accounting and Economics 41 (1-2): 147-171.

John, K., L. Litov, B. Yeung. 2008. Corporate Governance and Risk-Taking. The Journal of Finance 63: 1679-1728.

Jones, J.J. 1991. Earnings Management During Import Relief Investigations. Journal of Accounting Research 29 (2): 193-228.

Kahneman, D. and A. Tversky. 1979. Prospect Theory: An Analysis of Decision under Risk. Econometrica 47 (2): 263-292.

Kyle, A., and F. A. Wang. 1997. Speculation Duopoly with Agreement to Disagree: Can Overconfidence Survive the Market Test? Journal of Finance 52 (5): 2073-2090.

Masulis, R.W., P.K. Pham, and J. Zein. 2011. Family Business Groups around the World: Financing Advantages, Control Motivations, and Organizational Choices. Review of Financial Studies 24 (11): 3556-3600.

Newcomb, S. 1881. Note on the Frequency of Use of the Different Digits in Natural Numbers. American Journal of Mathematics 4(1): 39-40.

Nigrini, M.J. 1996. A Taxpayer Compliance Application of Benford's Law. Journal of the American Taxation Association 18 (1): 72-91.

Nigrini, M.J., and L.J. Mittermaier. 1997. The Use of Benford's Law As an Aid in Analytical Procedures. Auditing 16 (2): 52-67. 
Noreen, E. 1989. Computer-Intensive Methods for Testing Hypotheses: An Introduction. New York City, NY: Wiley.

Odean, T. 1998. Are Investors Reluctant to Realize Their Losses? Journal of Finance 53 (5): 1775-1798.

Peng, L., and W. Xiang. 2006. Investor attention, overconfidence, and category learning. Journal of Financial Economics 80: 563-602.

Poltrock, S., and D. Schwartz. 1984. Comparative judgments of multidigit numbers. Journal of Experimental Psychology: Learnings, Memory, and Cognition 10 (1): 32-45.

Randles, R. 2001. On Neutral Responses (Zeros) in the Sign Test and Ties in the WilcoxonMann-Whitney Test. The American Statistician. 55 (2): 96-101.

Rees, L. and K. Sivaramakrishnan. 2007. The Effect of Meeting or Beating Revenue Forecasts on the Association between Quarterly Returns and Earnings Forecast Errors. Contemporary Accounting Research 24 (1): 259-290.

Rosch, E., 1975. Cognitive Reference Points. Cognitive Psychology 7 (4): 532-547.

Rowland, M. 1990. Self-reported weight and height. The American Journal of Clinical Nutrition. December 199052 (6): 1125-1133.

Roychowdhury, S. 2006. Earnings Management Through Real Activities Manipulation. Journal of Accounting and Economics 42 (3): 335-370.

Schindler, R., and P. Kirby. 1997. Patterns of Rightmost Digits Used in Advertised Prices: Implications for Nine-Ending Effects. Journal of Consumer Research 24 (2): 192-201.

Schindler, R., and A. Wiman. 1989. Effects of odd pricing on price recall. Journal of Business Research 19 (3): 165-177.

Securities and Exchange Commission. 1999. SEC Staff Accounting Bulletin No. 99: Materiality.

Stiving, M., and R. Winer. 1997. An Empirical Analysis of Price Endings with Scanner Data. Journal of Consumer Research 24 (1): 57-67.

Stubben, S. 2010. Discretionary Revenues as a Measure of Earnings Management. The Accounting Review 85 (2): 695-717.

Swaminathan, S. and J. Weintrop. 1991. The Information Content of Earnings, Revenues, and Expenses. Journal of Accounting Research 29 (2): 418-427.

Tarrant, M., and M. Manfredo. 1993. Digit preference, recall bias, and nonresponsive bias in self reports of angling participation. Leisure Sciences 15 (3): 231-238. 
Thomas, J. 1989. Unusual Patterns in Reported Earnings. The Accounting Review 64 (4): 773787.

Turner, S. 1958. Patterns of heaping in the reporting of numerical data. Proceedings of the Social Statistics Section, American Statistical Association. Washington, D.C.: 248-251.

Tversky, A., and D. Kahneman. 1973. Availability: A heuristic for judging frequency and probability. Cognitive Psychology 5 (2): 207-232.

Visscher, T., L. Viet, H. Kroesbergen, and J. Seidell. (2006). Obesity. "Underreporting of BMI in Adults and Its Effect on Obesity Prevalence Estimations in the Period 1998 to 2001." Vol 14, No. 11: 2054-2063.

The Wall Street Journal 2015. Editorial board. “Obama Unchained.” February 2, 2015.

Whynes, D., Z. Philips, and E. Frew. 2005. Think of a number...any number? Health Economics 14: 1191-1195.

Zang, A. 2012. Evidence on the Trade-Off between Real Activities Manipulation and AccrualBased Earnings Management. The Accounting Review 87 (2): 675-703. 


\section{APPENDIX 1 \\ Examples of Organizations Reporting Salient Numbers Around Base-Ten Thresholds}

\section{Starbucks: “Poised To Join \$1 Billion-a-Year Club" (September 1997)}

In September 1997 Starbucks Chairman Howard Schultz spoke to investors about current and future financial performance. Schultz forecasted sales for the current period of $\$ 950$ to $\$ 980$ million, and predicted that sales would exceed $\$ 1$ billion in the next fiscal year. This focus on reaching \$1 billion in sales led to several news articles highlighting this point. The Seattle Times included an article titled "Starbucks Poised to Join \$1 Billion-a-year Club" on September 21, 1997. This article was picked up by other news agencies, including the Orlando Sentinel.

\section{Callaway Golf: "Exceeded the billion-dollar mark" (April 2007)}

The President and CEO of Callaway Golf George Fellows made a point to specifically highlight reaching \$1 billion in sales for the first time in the 2006 annual report. The firm reported annual sales of $\$ 1.018$ billion, and Fellows stated that for "the first time we have exceeded the billiondollar mark" in his $25^{\text {th }}$ Anniversary of Callaway Golf Company letter to shareholders.

\section{Heinz: Achieves Record Sales of Over \$10 Billion (May 2008)}

H.J. Heinz Company reported $12 \%$ sales growth to post record sales of $\$ 10.1$ billion for fiscal year 2007. Reaching this sales threshold led Business Wire to publish an article titled "Heinz Achieves Record Sales of Over \$10 Billion...” on May 29, 2008.

\section{Facebook: First Reported Earnings of \$1.000 billion (February 2012)}

Facebook Inc. went public in May 2012. In February 2012 the company publicly released its full financial results for the first time in its history. The most recent earnings reported in that first public release were for the year ended December 31, 2011. The reported earnings amount was exactly $\$ 1.000$ billion. One conclusion is that Facebook wanted to make sure that in the run-up to its long-anticipated IPO the company would enhance its reputation among investors by financially elevating itself above the ranks of small, startup technology companies into the elite set of "billion dollar companies."

\section{U.S. Federal Government 2016 Budget Proposal (February 2015)}

A "negative" threshold effect is evident in the fiscal 2016 federal budget submitted by U.S. President Obama in February 2015. The president's budget proposed fiscal 2016 spending of \$3.99 trillion. The Wall Street Journal editorial board found something strategic in this particular number, writing: "The budget gnomes must have been told that, whatever you do, keep the top line below \$4 trillion.” (The Wall Street Journal. Editorial board. “Obama Unchained.” February 2, 2015.) 


\section{APPENDIX 2 Minimum Observation Criterion}

Although we identify 53 potential salient thresholds that we test using our approximate randomization technique, not all 53 thresholds are included in all analyses reported in the paper. In particular, the most extreme small and large thresholds are sometimes excluded from the

analysis using certain bin widths in order to avoid distorted results from small sample sizes in the tails of the distribution. We impose restrictions based on the sample size and bin width. Our baseline bin width is 0.0100 . For analyses using this bin width, the minimum number of observations is $0.0075 \%$ of the sample size, rounded up to the nearest integer. All other bin widths have a similar minimum number, based on their size relative to 0.0100 ; for example, the 0.1000 bin width analysis requires 10 times as many observations, and the 0.0010 bin width analysis requires one-tenth the number of observations. All potential thresholds that lie beyond thresholds that were excluded because of small numbers of observations are also excluded; that is, we "cut off the tails." This procedure generally excludes the most extreme top and bottom $1 \%$ of the data, and similar results are obtained when simply truncating the data. The smallest number of threshold points included in our main tests using our minimum observations criterion is 43 (for the 0.0010 bin width) and the largest number of threshold points included is 53 (for the 0.0250 and 0.0400 bin widths). 


\section{Table 1. Number of Firm-Year Observations}

\begin{tabular}{|c|c|c|c|}
\hline \multicolumn{4}{|c|}{ By Decade and Data Source } \\
\hline & Total & Compustat & Osiris \\
\hline $50 \mathrm{~s}$ and $60 \mathrm{~s}$ & 32,651 & 32,651 & 0 \\
\hline $70 \mathrm{~s}$ & 52,257 & 52,257 & 0 \\
\hline $80 \mathrm{~s}$ & 77,209 & 67,233 & 9,976 \\
\hline $90 \mathrm{~s}$ & 142,718 & 89,135 & 53,583 \\
\hline $2000 \mathrm{~s}$ & 287,081 & 79,423 & 207,658 \\
\hline 2010s* & 149,133 & 30,246 & 118,887 \\
\hline & 741,049 & 350,945 & 390,104 \\
\hline
\end{tabular}

Observations from Compustat and Osiris are required to have non-missing values of current total assets and revenues. Unconsolidated entities are excluded. The Osiris data exclude all U.S. firms .

*2010-2014 


\section{Table 2. Distribution of Revenue Observations Around Base-Ten Thresholds \\ Bin Width: $\log 0.0010=0.23 \%$}

\section{Panel A: All Base-Ten Thresholds}

For all Thresholds of the form $\mathrm{T}=\mathrm{N} \times 10^{\mathrm{K}}$, for integers $\mathrm{N}$ (1 through 9) and $\mathrm{K}$ (5 through 10) for which a minimum number of observations exist in the ABOVE and BELOW bins (see Appendix 2). For the Log 0.0010 bin width, 43 threshold points (from $\$ 500,000$ through $\$ 20,000,000$ ) have the minumum number of observations.

\begin{tabular}{|c|c|c|c|c|c|}
\hline \multirow[b]{2}{*}{$\begin{array}{l}\text { Base-Ten } \\
\text { Threshold Point }\end{array}$} & \multirow[b]{2}{*}{ Log Value } & \multicolumn{2}{|c|}{ Number of Observations in } & & \multirow[b]{2}{*}{$\begin{array}{l}\text { Binomial p- } \\
\text { value }\end{array}$} \\
\hline & & $\begin{array}{c}\text { Bin } 0.23 \% \text { BELOW } \\
\text { Threshold Point }\end{array}$ & $\begin{array}{c}\text { Bin } 0.23 \% \text { ABOVE } \\
\text { Threshold Point }\end{array}$ & $\begin{array}{c}\text { Ratio } \\
\text { ABOVE/BELOW } \\
\left(S_{0.0010}\right)\end{array}$ & \\
\hline$\$ 500,000$ & 5.698970 & 12 & 63 & 5.25 & $\mathbf{0 . 0 0 0}$ \\
\hline$\$ 600,000$ & 5.778151 & 9 & 37 & 4.11 & 0.000 \\
\hline$\$ 700,000$ & 5.845098 & 15 & 34 & 2.27 & 0.005 \\
\hline$\$ 800,000$ & 5.903090 & 13 & 41 & 3.15 & 0.000 \\
\hline$\$ 900,000$ & 5.954243 & 21 & 53 & 2.52 & 0.000 \\
\hline$\$ 1,000,000$ & 6.000000 & 24 & 59 & 2.46 & 0.000 \\
\hline$\$ 2,000,000$ & 6.301030 & 30 & 73 & 2.43 & 0.000 \\
\hline$\$ 3,000,000$ & 6.477121 & 29 & 82 & 2.83 & 0.000 \\
\hline$\$ 4,000,000$ & 6.602060 & 40 & 101 & 2.53 & 0.000 \\
\hline$\$ 5,000,000$ & 6.698970 & 44 & 117 & 2.66 & 0.000 \\
\hline$\$ 6,000,000$ & 6.778151 & 62 & 112 & 1.81 & 0.000 \\
\hline$\$ 7,000,000$ & 6.845098 & 51 & 122 & 2.39 & 0.000 \\
\hline$\$ 8,000,000$ & 6.903090 & 80 & 129 & 1.61 & 0.000 \\
\hline$\$ 9,000,000$ & 6.954243 & 78 & 121 & 1.55 & 0.001 \\
\hline$\$ 10,000,000$ & 7.000000 & 66 & 148 & 2.24 & 0.000 \\
\hline$\$ 20,000,000$ & 7.301030 & 81 & 145 & 1.79 & 0.000 \\
\hline$\$ 30,000,000$ & 7.477121 & 104 & 161 & 1.55 & 0.000 \\
\hline$\$ 40,000,000$ & 7.602060 & 93 & 148 & 1.59 & 0.000 \\
\hline$\$ 50,000,000$ & 7.698970 & 122 & 167 & 1.37 & 0.005 \\
\hline$\$ 60,000,000$ & 7.778151 & 119 & 143 & 1.20 & 0.078 \\
\hline$\$ 70,000,000$ & 7.845098 & 124 & 140 & 1.13 & 0.178 \\
\hline$\$ 80,000,000$ & 7.903090 & 111 & 153 & 1.38 & 0.006 \\
\hline$\$ 90,000,000$ & 7.954243 & 127 & 162 & 1.28 & 0.023 \\
\hline$\$ 100,000,000$ & 8.000000 & 101 & 162 & 1.60 & 0.000 \\
\hline$\$ 200,000,000$ & 8.301030 & 93 & 137 & 1.47 & 0.002 \\
\hline$\$ 300,000,000$ & 8.477121 & 99 & 122 & 1.23 & 0.069 \\
\hline$\$ 400,000,000$ & 8.602060 & 92 & 118 & 1.28 & 0.042 \\
\hline$\$ 500,000,000$ & 8.698970 & 88 & 129 & 1.47 & 0.003 \\
\hline$\$ 600,000,000$ & 8.778151 & 83 & 116 & 1.40 & 0.012 \\
\hline$\$ 700,000,000$ & 8.845098 & 74 & 89 & 1.20 & 0.136 \\
\hline$\$ 800,000,000$ & 8.903090 & 66 & 86 & 1.30 & 0.062 \\
\hline$\$ 900,000,000$ & 8.954243 & 77 & 85 & 1.10 & 0.291 \\
\hline
\end{tabular}




\begin{tabular}{rrrrrr}
$\$ 1,000,000,000$ & 9.000000 & 53 & 86 & 1.62 & $\mathbf{0 . 0 0 3}$ \\
$\$ 2,000,000,000$ & 9.301030 & 55 & 75 & 1.36 & $\mathbf{0 . 0 4 8}$ \\
$\$ 3,000,000,000$ & 9.477121 & 46 & 46 & 1.00 & 0.541 \\
$\$ 4,000,000,000$ & 9.602060 & 31 & 38 & 1.23 & 0.235 \\
$\$ 5,000,000,000$ & 9.698970 & 29 & 38 & 1.31 & 0.164 \\
$\$ 6,000,000,000$ & 9.778151 & 23 & 39 & 1.70 & $\mathbf{0 . 0 2 8}$ \\
$\$ 7,000,000,000$ & 9.845098 & 27 & 26 & 0.96 & 0.608 \\
$\$ 8,000,000,000$ & 9.903090 & 29 & 27 & 0.93 & 0.656 \\
$\$ 9,000,000,000$ & 9.954243 & 27 & 27 & 1.00 & 0.554 \\
$\$ 10,000,000,000$ & 10.000000 & 13 & 26 & 2.00 & $\mathbf{0 . 0 2 7}$ \\
$\$ 20,000,000,000$ & 10.301030 & 11 & 14 & 1.27 & 0.345 \\
\hline
\end{tabular}

\section{Panel B : Most Prominent Base-Ten Thresholds}

For all Thresholds of the form $\mathrm{T}=10^{\mathrm{K}}$, for integers $\mathrm{K}$ (5 through 10)

\begin{tabular}{|c|c|c|c|c|c|}
\hline \multirow[b]{2}{*}{$\begin{array}{c}\text { Base-Ten } \\
\text { Threshold Point }\end{array}$} & \multirow[b]{2}{*}{ Log Value } & \multicolumn{2}{|c|}{ Number of Observations in } & & \multirow[b]{2}{*}{$\begin{array}{c}\text { Binomial p- } \\
\text { value }\end{array}$} \\
\hline & & $\begin{array}{c}\text { Bin } 0.23 \% \text { BELOW } \\
\text { Threshold Point }\end{array}$ & $\begin{array}{c}\text { Bin } 0.23 \% \text { ABOVE } \\
\text { Threshold Point }\end{array}$ & $\begin{array}{c}\text { Ratio } \\
\text { ABOVE/BELOW } \\
\left(S_{0.0010}\right)\end{array}$ & \\
\hline$\$ 1,000,000$ & 6 & 24 & 59 & 2.46 & 0.000 \\
\hline$\$ 10,000,000$ & 7 & 66 & 148 & 2.24 & 0.000 \\
\hline$\$ 100,000,000$ & 8 & 101 & 162 & 1.60 & 0.000 \\
\hline$\$ 1,000,000,000$ & 9 & 53 & 86 & 1.62 & 0.003 \\
\hline$\$ 10,000,000,000$ & 10 & 13 & 26 & 2.00 & $\mathbf{0 . 0 2 7}$ \\
\hline \multicolumn{2}{|c|}{ Prominent Thresholds Combined } & 257 & 481 & 1.87 & 0.000 \\
\hline
\end{tabular}

Approximate randomization p-values significant at the 5\% level bolded. 


\section{Table 3. Approximate Randomization Threshold Tests \\ Ratio of Above to Below Revenue Observations \\ Bin Widths: $\log 0.0010(0.23 \%)-\log 0.1000(25.89 \%)$}

\begin{tabular}{|c|c|c|c|c|c|c|}
\hline \multicolumn{7}{|c|}{ Panel A: All Base-Ten Thresholds, All B in Widths } \\
\hline \multicolumn{7}{|c|}{ For all Thresholds of the form $\mathrm{T}=\mathrm{N} \times 10^{\mathrm{K}}$, for integers $\mathrm{N}(1$ through 9$)$ and $\mathrm{K}$ ( 5 through 10$)$} \\
\hline \multirow[b]{2}{*}{$\begin{array}{l}\text { Bin Width (in } \\
\text { terms of the } \\
\text { common log of } \\
\text { revenue) }\end{array}$} & \multirow[b]{2}{*}{$\begin{array}{l}\text { Bin Width (in } \\
\text { terms of } \\
\text { percentage of } \\
\text { revenue) }\end{array}$} & \multicolumn{2}{|c|}{ Number of Observations in } & \multirow[b]{2}{*}{$\begin{array}{c}\text { Ratio } \\
\text { ABOVE/BELOW } \\
\left(S_{j}\right)\end{array}$} & \multirow[b]{2}{*}{$\begin{array}{c}\text { Binomial } \\
\text { p-value }\end{array}$} & \multirow[b]{2}{*}{$\begin{array}{c}\text { Approximate } \\
\text { Randomization } \\
\text { p-value }\end{array}$} \\
\hline & & $\begin{array}{c}\text { Bin BELOW } \\
\text { Threshold } \\
\text { Points }\end{array}$ & $\begin{array}{c}\text { Bin ABOVE } \\
\text { Threshold } \\
\text { Points }\end{array}$ & & & \\
\hline 0.0010 & $0.23 \%$ & 2,572 & 3,997 & 1.554 & 0.0000 & 0.0001 \\
\hline 0.0025 & $0.58 \%$ & 8,557 & 10,349 & 1.209 & 0.0000 & 0.0001 \\
\hline 0.0050 & $1.16 \%$ & 14,560 & 16,783 & 1.153 & 0.0000 & 0.0001 \\
\hline 0.0100 & $2.33 \%$ & 29,922 & 32,475 & 1.085 & 0.0000 & 0.0001 \\
\hline 0.0200 & $4.71 \%$ & 60,767 & 63,459 & 1.044 & 0.0000 & 0.0001 \\
\hline 0.0250 & $5.93 \%$ & 76,264 & 79,150 & 1.038 & 0.0000 & 0.0001 \\
\hline 0.0400 & $9.65 \%$ & 122,585 & 125,296 & 1.022 & 0.0000 & 0.0001 \\
\hline 0.0500 & $12.20 \%$ & 153,506 & 156,307 & 1.018 & 0.0000 & 0.0015 \\
\hline 0.0750 & $18.85 \%$ & 231,680 & 234,206 & 1.011 & 0.0001 & 0.0790 \\
\hline 0.1000 & $25.89 \%$ & 309,411 & 311,745 & 1.008 & 0.0015 & 0.2216 \\
\hline
\end{tabular}

\section{Panel B: Incremental Observations -- All Base-Ten Thresholds, All Band Widths}

For all Thresholds of the form $\mathrm{T}=\mathrm{N} \times 10^{\mathrm{K}}$, for integers $\mathrm{N}$ (1 through 9) and $\mathrm{K}$ (5 through 10)

\begin{tabular}{|c|c|c|c|c|c|c|}
\hline \multirow[b]{2}{*}{$\begin{array}{c}\text { Band Width (in } \\
\text { terms of the } \\
\text { common log of } \\
\text { revenue) }\end{array}$} & \multirow[b]{2}{*}{$\begin{array}{c}\text { Band Width (in } \\
\text { terms of } \\
\text { percentage of } \\
\text { revenue) }\end{array}$} & \multicolumn{2}{|c|}{ Number of Observations in } & \multirow[b]{2}{*}{$\begin{array}{c}\text { Ratio } \\
\text { ABOVE/BELOW } \\
\left(S_{j-(j-1)}\right) \\
\end{array}$} & \multirow[b]{2}{*}{$\begin{array}{c}\text { Binomial } \\
\text { p-value }\end{array}$} & \multirow[b]{2}{*}{$\begin{array}{c}\text { Approximate } \\
\text { Randomization } \\
\text { p-value }\end{array}$} \\
\hline & & $\begin{array}{c}\text { Band BELOW } \\
\text { Threshold } \\
\text { Points } \\
\end{array}$ & $\begin{array}{c}\text { Band ABOVE } \\
\text { Threshold } \\
\text { Points } \\
\end{array}$ & & & \\
\hline 0 to 0.0010 & 0 to $0.23 \%$ & 2,572 & 3,997 & 1.554 & 0.0000 & 0.0001 \\
\hline 0.0010 to 0.0025 & $0.23 \%$ to $0.58 \%$ & 5,955 & 6,213 & 1.043 & 0.0099 & 0.0044 \\
\hline 0.0025 to 0.0050 & $0.58 \%$ to $1.16 \%$ & 5,994 & 6,353 & 1.060 & 0.0006 & 0.0001 \\
\hline 0.0050 to 0.0100 & $1.16 \%$ to $2.33 \%$ & 15,362 & 15,692 & 1.021 & 0.0310 & 0.0123 \\
\hline 0.0100 to 0.0200 & $2.33 \%$ to $4.71 \%$ & 30,883 & 31,021 & 1.004 & 0.2909 & 0.2675 \\
\hline 0.0200 to 0.0250 & $4.71 \%$ to $5.93 \%$ & 15,351 & 15,556 & 1.013 & 0.1229 & 0.0989 \\
\hline 0.0250 to 0.0400 & $5.93 \%$ to $9.65 \%$ & 46,321 & 46,146 & 0.996 & 0.7186 & 0.6866 \\
\hline 0.0400 to 0.0500 & $9.65 \%$ to $12.20 \%$ & 31,026 & 31,123 & 1.003 & 0.3501 & 0.3836 \\
\hline 0.0500 to 0.0750 & $12.20 \%$ to $18.85 \%$ & 78,174 & 77,899 & 0.996 & 0.7576 & 0.6209 \\
\hline 0.0750 to 0.1000 & $18.85 \%$ to $25.89 \%$ & 77,731 & 77,539 & 0.998 & 0.6879 & 0.5526 \\
\hline
\end{tabular}

Effect in reported revenues. Results for the full set of all Base-Ten thresholds is given in Panel A. In Panel B are results for only the INCREMENTAL observations for each bin width, those within the given bin width that are not included in the next smaller bin width. Each panel provides statistics for a variety of logged bin widths, including the number of observations in the bins just above and below the threshold points, the associated binomial test p-value (assuming an equal probability of observations falling in either bin), and the ratio of the observations in the above and below bins (the test statistic used to generate the approximate randomization pvalue). Approximate randomization p-values significant at the $5 \%$ level bolded. 
Table 4. Ratio-of-Ratios Threshold Tests

Comparing the Threshold Effect of Revenue to that of Cost of Goods Sold, Total Assets, and Market Value of Equity

Bin Widths: $\log 0.0010(0.23 \%)-\log 0.0100(2.33 \%)$

\section{Panel A: All Base-Ten Thresholds, Revenue and Cost of Goods Sold Comparison}

For all Thresholds of the form $\mathrm{T}=\mathrm{N} \times 10^{\mathrm{K}}$, for integers $\mathrm{N}$ (1 through 9 ) and $\mathrm{K}$ (5 through 10)

\begin{tabular}{cccccc}
$\begin{array}{c}\text { Bin Width }(\text { in } \\
\text { terms of the } \\
\text { common log of } \\
\text { revenue })\end{array}$ & $\begin{array}{c}\text { Bin Width (in } \\
\text { terms of } \\
\text { percentage of } \\
\text { revenue })\end{array}$ & $\begin{array}{c}\text { Revenue Ratio } \\
\text { ABOVE/BELOW } \\
\left(S_{j, \text { Revenue }}\right)\end{array}$ & $\begin{array}{c}\text { Cost of Goods } \\
\text { Sold Ratio } \\
\text { ABOVE/BELOW } \\
\left(S_{j, \text { COGS }}\right)\end{array}$ & $\begin{array}{c}\text { Ratio of Ratios } \\
\left(V_{j}=\right.\end{array}$ & $\begin{array}{c}\left.S_{j, \text { Revenue }} / S_{j, \text { COGS }}\right) \\
\text { Randomization } \\
\text { p-value }\end{array}$ \\
\hline 0.0010 & $0.23 \%$ & 1.554 & 1.086 & 1.430 & $\mathbf{0 . 0 0 0 1}$ \\
0.0025 & $0.58 \%$ & 1.209 & 1.033 & 1.170 & $\mathbf{0 . 0 0 0 1}$ \\
0.0050 & $1.16 \%$ & 1.153 & 1.025 & 1.124 & $\mathbf{0 . 0 0 0 1}$ \\
0.0100 & $2.33 \%$ & 1.085 & 1.010 & 1.075 & $\mathbf{0 . 0 0 0 1}$
\end{tabular}

Panel B: All Base-Ten Thresholds, Revenue and Total Assets Comparison

For all Thresholds of the form $\mathrm{T}=10^{\mathrm{K}}$, for integers $\mathrm{K}$ (5 through 10)

\begin{tabular}{|c|c|c|c|c|c|}
\hline $\begin{array}{l}\text { Bin Width (in } \\
\text { terms of the } \\
\text { common log of } \\
\text { revenue) }\end{array}$ & $\begin{array}{l}\text { Bin Width (in } \\
\text { terms of } \\
\text { percentage of } \\
\text { revenue) } \\
\end{array}$ & $\begin{array}{c}\text { Revenue Ratio } \\
\text { ABOVE/BELOW } \\
\left(S_{j, \text { Revenue }}\right) \\
\end{array}$ & $\begin{array}{c}\text { Total Assets } \\
\text { Ratio } \\
\text { ABOVE/BELOW } \\
\left(S_{j, A s s e t s}\right) \\
\end{array}$ & $\begin{array}{c}\text { Ratio of Ratios } \\
\left(V_{j}=\right. \\
\left.S_{j, \text { Revenue }} / S_{j, \text { Assets }}\right)\end{array}$ & $\begin{array}{c}\text { Approximate } \\
\text { Randomization } \\
\text { p-value } \\
\end{array}$ \\
\hline 0.0010 & $0.23 \%$ & 1.554 & 1.298 & 1.197 & 0.0001 \\
\hline 0.0025 & $0.58 \%$ & 1.209 & 1.107 & 1.093 & 0.0001 \\
\hline 0.0050 & $1.16 \%$ & 1.153 & 1.074 & 1.074 & 0.0001 \\
\hline 0.0100 & $2.33 \%$ & 1.085 & 1.050 & 1.034 & 0.0006 \\
\hline
\end{tabular}

\section{Panel C: All Base-Ten Thresholds, Revenue and Market Value of Equity Comparison}

For all Thresholds of the form $\mathrm{T}=10^{\mathrm{K}}$, for integers $\mathrm{K}$ (5 through 10)

\begin{tabular}{|c|c|c|c|c|c|}
\hline $\begin{array}{l}\text { Bin Width (in } \\
\text { terms of the } \\
\text { common log of } \\
\text { revenue) }\end{array}$ & $\begin{array}{l}\text { Bin Width (in } \\
\text { terms of } \\
\text { percentage of } \\
\text { revenue) } \\
\end{array}$ & $\begin{array}{c}\text { Revenue Ratio } \\
\text { ABOVE/BELOW } \\
\left(S_{j, \text { Revenue }}\right)\end{array}$ & $\begin{array}{c}\text { Market Value of } \\
\text { Equity Ratio } \\
\text { ABOVE/BELOW } \\
\left(S_{j, M V E}\right) \\
\end{array}$ & $\begin{array}{c}\text { Ratio of Ratios } \\
\left(V_{j}=\right. \\
\left.S_{j, \text { Revenue }} / S_{j, M V E}\right) \\
\end{array}$ & $\begin{array}{c}\text { Approximate } \\
\text { Randomization } \\
\text { p-value }\end{array}$ \\
\hline 0.0010 & $0.23 \%$ & 1.554 & 1.082 & 1.437 & 0.0001 \\
\hline 0.0025 & $0.58 \%$ & 1.209 & 1.012 & 1.195 & 0.0001 \\
\hline 0.0050 & $1.16 \%$ & 1.153 & 1.007 & 1.145 & 0.0001 \\
\hline 0.0100 & $2.33 \%$ & 1.085 & 1.013 & 1.072 & 0.0001 \\
\hline
\end{tabular}

This table presents the results of approximate randomization tests estimating the significance of the Threshold Effect for reported revenues relative to that of cost of goods sold, total as sets, and market value of equity. Results for the full set of all Base-Ten thresholds relative to cost of goods sold, total assets, and market value of equity are given in Panels A, B, and C, respectively. Each panel provides statistics for a variety of logged bin widths, including the ratio of the number of observations in the bins just above and below the threshold points for revenue, cost of goods sold, total assets, and market value of equity, as well as the ratio of the revenue ratios to the ratios of the three comparis on items (the test statistic used to generate the approximate randomization p-value). Approximate randomization p-values significant at the $5 \%$ level are bolded. 
Table 5. Ratio-of-Ratios Threshold Tests: Non-U.S. Firms

Demonstrating the Existence of the Threshold Effect in a Variety of Countries and Currencies

Bin Widths: $\log 0.0010(0.23 \%)$ - $\log 0.0100(2.33 \%)$

\section{Panel A: All Base-Ten Thresholds, All Bin Widths, Revenue and Cost of Goods Sold Comparison}

For all Thresholds of the form $\mathrm{T}=\mathrm{N} \times 10^{\mathrm{K}}$, for integers $\mathrm{N}$ (1 through 9) and $\mathrm{K}(5$ through 10)

\begin{tabular}{cccccc}
$\begin{array}{c}\text { Bin Width }(\text { in } \\
\text { terms of the }\end{array}$ & $\begin{array}{c}\text { Bin Width (in } \\
\text { terms of } \\
\text { common log of } \\
\text { revenue) }\end{array}$ & $\begin{array}{c}\text { Revenue Ratio } \\
\text { percentage of } \\
\text { revenue })\end{array}$ & $\begin{array}{c}\text { Cost ofGoods } \\
\text { Sold Ratio } \\
\left(S_{j, \text { Revenue }}\right)\end{array}$ & $\begin{array}{c}\text { Ratio of Ratios } \\
\left(V_{j}=\right.\end{array}$ & $\begin{array}{c}\text { Approximate } \\
\text { Randomization } \\
\text { ( }\end{array}$ \\
\hline 0.0010 & $0.23 \%$ & 1.218 & 1.121 & 1.086 & $\mathbf{p}$-value \\
0.0025 & $0.58 \%$ & 1.128 & 1.053 & 1.071 & $\mathbf{0 . 0 3 3 7}$ \\
0.0050 & $1.16 \%$ & 1.117 & 1.034 & 1.081 & $\mathbf{0 . 0 0 3 1}$ \\
0.0100 & $2.33 \%$ & 1.081 & 1.030 & 1.050 & $\mathbf{0 . 0 0 0 2}$ \\
& & & & & $\mathbf{0 . 0 0 0 4}$ \\
\hline
\end{tabular}

\section{Panel B: Most Prominent Base-Ten Thresholds, All Bin Widths, Revenue and Cost of Goods Sold Comparison}

For all Thresholds of the form $\mathrm{T}=10^{\mathrm{K}}$, for integers $\mathrm{K}$ (5 through 10$)$

\begin{tabular}{cccccc}
$\begin{array}{c}\text { Bin Width } \text { (in } \\
\text { terms of the } \\
\text { common log of } \\
\text { revenue })\end{array}$ & $\begin{array}{c}\text { Bin Width (in } \\
\text { terms of } \\
\text { percentage of } \\
\text { revenue })\end{array}$ & $\begin{array}{c}\text { Revenue Ratio } \\
\text { ABOVE/BELOW } \\
\left(S_{j, \text { Revenue }}\right)\end{array}$ & $\begin{array}{c}\text { Cost of Soods } \\
\text { Sold Ratio } \\
\left(S_{j, \text { COGS }}\right)\end{array}$ & $\begin{array}{c}\text { Ratio of Ratios } \\
\left(V_{j}=\right.\end{array}$ & $\begin{array}{c}\text { Approximate } \\
\text { Randomization }\end{array}$ \\
\hline 0.0010 & $0.23 \%$ & 1.427 & 1.152 & 1.239 & $\mathbf{0 . 0 3 0 2}$ \\
0.0025 & $0.58 \%$ & 1.281 & 1.057 & 1.212 & $\mathbf{0 . 0 0 3 1}$ \\
0.0050 & $1.16 \%$ & 1.200 & 1.006 & 1.194 & $\mathbf{0 . 0 0 0 5}$ \\
0.0100 & $2.33 \%$ & 1.147 & 1.019 & 1.126 & $\mathbf{0 . 0 0 1 5}$ \\
\hline
\end{tabular}

This table presents the results of approximate randomization tests estimating the significance of the Threshold Effect for reported revenues relative to that of cost of goods sold for a set of non-U.S. firms reporting in a variety of currencies. The data in this table are taken from the Osiris database, as described in the discussion of Table 1. Results for the full set of all Base-Ten thresholds and the set of only the most prominent thresholds are given in Panels A and B, respectively. Each panel provides statistics for a variety of logged bin widths, including the ratio of the number of observations in the bins just above and below the threshold points for both revenue and cost of goods sold, as well as the ratio of these ratios (the test statistic used to generate the approximate randomization $\mathrm{p}$ value). Approximate randomization p-values significant at the $5 \%$ level bolded. 
Table 6. Analyst Revenue Forecast Threshold Tests

Comparing the Threshold Effect of Analyst Revenue Forecasts Over Time and to Actual Revenue

Bin Widths 0.0010 - 0.0100

\section{Panel A: First Analyst Revenue Forecast Compared to Actual Cost of Goods Sold}

For all Thresholds of the form $\mathrm{T}=\mathrm{N} \times 10^{\mathrm{K}}$, for integers $\mathrm{N}$ (1 through 9) and $\mathrm{K}$ (5 through 10)

\begin{tabular}{|c|c|c|c|c|c|}
\hline $\begin{array}{c}\text { Bin Width (in terms } \\
\text { of the common log } \\
\text { of revenue) }\end{array}$ & $\begin{array}{c}\text { Bin Width (in terms } \\
\text { ofpercentage of } \\
\text { revenue) }\end{array}$ & $\begin{array}{c}\text { First Revenue } \\
\text { Forecast Ratio } \\
\text { ABOVE/BELOW } \\
\left(S_{j, \text { First_Rev }}\right)\end{array}$ & $\begin{array}{c}\text { Actual Cost of } \\
\text { Goods Sold Ratio } \\
\text { ABOVE/BELOW } \\
\left(S_{j, \text { COGS }}\right)\end{array}$ & $\begin{array}{c}\text { Ratio of Ratios } \\
\left(V_{j}=\right. \\
\left.S_{j, \text { First_Rev }} / S_{j, \text { COGS }}\right)\end{array}$ & $\begin{array}{c}\text { Approximate } \\
\text { Randomization } \\
\text { p-value }\end{array}$ \\
\hline 0.0010 & $0.23 \%$ & 1.955 & 1.086 & 1.800 & 0.0001 \\
\hline 0.0025 & $0.58 \%$ & 1.360 & 1.033 & 1.316 & 0.0001 \\
\hline 0.0050 & $1.16 \%$ & 1.229 & 1.025 & 1.199 & 0.0001 \\
\hline 0.0100 & $2.33 \%$ & 1.119 & 1.010 & 1.109 & 0.0001 \\
\hline
\end{tabular}

Panel B: Last Analyst Revenue Forecast Compared to Actual Cost of Goods Sold

For all Thresholds of the form $\mathrm{T}=\mathrm{N} \times 10^{\mathrm{K}}$, for integers $\mathrm{N}$ (1 through 9) and $\mathrm{K}$ (5 through 10)

\begin{tabular}{|c|c|c|c|c|c|}
\hline $\begin{array}{c}\text { Bin Width (in terms } \\
\text { of the common log } \\
\text { of revenue) }\end{array}$ & $\begin{array}{c}\text { Bin Width (in terms } \\
\text { ofpercentage of } \\
\text { revenue) }\end{array}$ & $\begin{array}{c}\text { Last Revenue } \\
\text { Forecast Ratio } \\
\text { ABOVE/BELOW } \\
\left(S_{j, \text { Last_Rev }}\right) \\
\end{array}$ & $\begin{array}{c}\text { Actual Cost of } \\
\text { Goods Sold Ratio } \\
\text { ABOVE/BELOW } \\
\left(S_{j, \text { COGS }}\right) \\
\end{array}$ & $\begin{array}{c}\text { Ratio of Ratios } \\
\left(V_{j}=\right. \\
\left.S_{j, \text { Last_Rev }} / S_{j, \text { COGS }}\right) \\
\end{array}$ & $\begin{array}{c}\text { Approximate } \\
\text { Randomization } \\
p \text {-value } \\
\end{array}$ \\
\hline 0.0010 & $0.23 \%$ & 1.559 & 1.086 & 1.435 & 0.0001 \\
\hline 0.0025 & $0.58 \%$ & 1.233 & 1.033 & 1.193 & 0.0001 \\
\hline 0.0050 & $1.16 \%$ & 1.156 & 1.025 & 1.127 & 0.0001 \\
\hline 0.0100 & $2.33 \%$ & 1.098 & 1.010 & 1.087 & 0.0001 \\
\hline
\end{tabular}

\section{Panel C: First Analyst Revenue Forecast Compared to Last Analyst Revenue Forecast}

For all Thresholds of the form $\mathrm{T}=\mathrm{N} \times 10^{\mathrm{K}}$, for integers $\mathrm{N}$ (1 through 9) and $\mathrm{K}$ (5 through 10)

\begin{tabular}{|c|c|c|c|c|c|}
\hline $\begin{array}{c}\text { Bin Width (in terms } \\
\text { of the common log } \\
\text { of revenue) }\end{array}$ & $\begin{array}{c}\text { Bin Width (in terms } \\
\text { ofpercentage of } \\
\text { revenue) }\end{array}$ & $\begin{array}{c}\text { First Revenue } \\
\text { Forecast Ratio } \\
\text { ABOVE/BELOW } \\
\left(S_{j, \text { First_Rev }}\right) \\
\end{array}$ & $\begin{array}{c}\text { Last Revenue } \\
\text { Forecast Ratio } \\
\text { ABOVE/BELOW } \\
\left(S_{j, \text { Last_Rev }}\right) \\
\end{array}$ & $\begin{array}{c}\text { Ratio of Ratios } \\
\left(\begin{array}{c}V_{j}=S_{j, \text { First_Rev }} / \\
\left.S_{j, \text { Last_Rev }}\right)\end{array}\right.\end{array}$ & $\begin{array}{c}\text { Approximate } \\
\text { Randomization } \\
\text { p-value } \\
\end{array}$ \\
\hline 0.0010 & $0.23 \%$ & 1.955 & 1.559 & 1.254 & 0.0007 \\
\hline 0.0025 & $0.58 \%$ & 1.360 & 1.233 & 1.103 & 0.0012 \\
\hline 0.0050 & $1.16 \%$ & 1.229 & 1.156 & 1.064 & 0.0053 \\
\hline 0.0100 & $2.33 \%$ & 1.119 & 1.098 & 1.020 & 0.1404 \\
\hline
\end{tabular}




\section{Panel D: First Analyst Revenue Forecast Compared to Actual Revenue}

For all Thresholds of the form $\mathrm{T}=\mathrm{N} \times 10^{\mathrm{K}}$, for integers $\mathrm{N}$ (1 through 9) and $\mathrm{K}$ (5 through 10)

\begin{tabular}{|c|c|c|c|c|c|}
\hline $\begin{array}{c}\text { Bin Width (in terms } \\
\text { of the common log } \\
\text { of revenue) }\end{array}$ & $\begin{array}{c}\text { Bin Width (in terms } \\
\text { ofpercentage of } \\
\text { revenue) }\end{array}$ & $\begin{array}{c}\text { First Revenue } \\
\text { Forecast Ratio } \\
\text { ABOVE/BELOW } \\
\left(S_{j, \text { First_Rev }}\right) \\
\end{array}$ & $\begin{array}{c}\text { Actual Revenue } \\
\text { Ratio } \\
\text { ABOVE/BELOW } \\
\left(S_{j, \text { Revenue }}\right) \\
\end{array}$ & $\begin{array}{c}\text { Ratio of Ratios } \\
\left(\begin{array}{c}V_{j}=S_{j, \text { First_Rev }} \\
\left.S_{j, \text { Revenue }}\right)\end{array}\right. \\
\end{array}$ & $\begin{array}{c}\text { Approximate } \\
\text { Randomization } \\
\text { p-value } \\
\end{array}$ \\
\hline 0.0010 & $0.23 \%$ & 1.955 & 1.554 & 1.258 & 0.0010 \\
\hline 0.0025 & $0.58 \%$ & 1.360 & 1.211 & 1.123 & 0.0001 \\
\hline 0.0050 & $1.16 \%$ & 1.229 & 1.153 & 1.066 & 0.0012 \\
\hline 0.0100 & $2.33 \%$ & 1.119 & 1.085 & 1.031 & 0.0142 \\
\hline
\end{tabular}

Panel E: Last Analyst Revenue Forecast Compared to Actual Revenue

For all Thresholds of the form $\mathrm{T}=\mathrm{N} \times 10^{\mathrm{K}}$, for integers $\mathrm{N}$ (1 through 9 ) and $\mathrm{K}$ (5 through 10)

\begin{tabular}{|c|c|c|c|c|c|}
\hline $\begin{array}{c}\text { Bin Width (in terms } \\
\text { of the common log } \\
\text { of revenue) }\end{array}$ & $\begin{array}{c}\text { Bin Width (in terms } \\
\text { ofpercentage of } \\
\text { revenue) }\end{array}$ & $\begin{array}{c}\text { Last Revenue } \\
\text { Forecast Ratio } \\
\text { ABOVE/BELOW } \\
\left(S_{j, \text { Last_Rev }}\right)\end{array}$ & $\begin{array}{c}\text { Actual Revenue } \\
\text { Ratio } \\
\text { ABOVE/BELOW } \\
\left(S_{j, \text { Revenue }}\right)\end{array}$ & $\begin{array}{c}\text { Ratio of Ratios } \\
\left(V_{j}=\right. \\
S_{j, \text { Last_Rev }} / S_{j, \text { Revenue }} \\
)\end{array}$ & $\begin{array}{c}\text { Approximate } \\
\text { Randomization } \\
\text { p-value }\end{array}$ \\
\hline 0.0010 & $0.23 \%$ & 1.559 & 1.554 & 1.003 & 0.6108 \\
\hline 0.0025 & $0.58 \%$ & 1.233 & 1.211 & 1.018 & 0.3109 \\
\hline 0.0050 & $1.16 \%$ & 1.156 & 1.153 & 1.003 & 0.5011 \\
\hline 0.0100 & $2.33 \%$ & 1.098 & 1.085 & 1.012 & 0.2469 \\
\hline
\end{tabular}

This table presents the results of approximate randomization tests estimating the significance of the Threshold Effect for analyst revenue forecasts. The first and the last forecast made by each analyst before the earnings announcement of a given period is compared to various control groups including actual cost of goods sold and actual revenue. Each panel presents results for the full set of all Base-Ten thresholds and provides statistics for four logged bin widths, including the ratio of the number of observations in the bins just above and below the threshold points as well as the ratio of these ratios (the test statistic used to generate the approximate randomization p-value). Approximate randomization p-values significant at the $5 \%$ level bolded. 


\section{Table 7. Past Revenue Growth and Price-to-Sales Ratio Threshold Tests \\ Comparing the Threshold Effect for Firms with High and Low Past Revenue Growth and High and Low Price-to-Sales Ratios}

Bin Widths 0.0010 - 0.0100

\begin{tabular}{|c|c|c|c|c|c|}
\hline \multicolumn{6}{|c|}{$\begin{array}{l}\text { Panel A: Firms with High Compared to Low Past Revenue Growth } \\
\left.\text { For all Thresholds of the form } \mathrm{T}=\mathrm{N} \times 10^{\mathrm{K}} \text {, for integers } \mathrm{N}(1 \text { through } 9) \text { and } \mathrm{K} \text { (5 through } 10\right)\end{array}$} \\
\hline $\begin{array}{l}\text { Bin Width (in } \\
\text { terms of the } \\
\text { common log of } \\
\text { revenue) }\end{array}$ & $\begin{array}{l}\text { Bin Width (in } \\
\text { terms of } \\
\text { percentage of } \\
\text { revenue) } \\
\end{array}$ & $\begin{array}{c}\text { Highest Past } \\
\text { Revenue Growth } \\
\text { Decile } \\
\text { ABOVE/BELOW } \\
\left(S_{j, \text { High_Growth }}\right)\end{array}$ & $\begin{array}{c}\text { Lowest Past Revenue } \\
\text { Growth Decile } \\
\text { ABOVE/BELOW } \\
\left(S_{j, L o w \_G r o w t h}\right)\end{array}$ & $\begin{array}{c}\text { Ratio of Ratios } \\
\quad(\text { Vj= } \\
S_{j, \text { High_Growth }} / \\
\left.S_{j, \text { Low_Growth }}\right)\end{array}$ & $\begin{array}{c}\text { Approximate } \\
\text { Randomization } \\
\text { p-value } \\
\end{array}$ \\
\hline 0.0010 & $0.23 \%$ & 1.647 & 1.349 & 1.221 & 0.0148 \\
\hline 0.0025 & $0.58 \%$ & 1.229 & 1.130 & 1.088 & 0.0286 \\
\hline 0.0050 & $1.16 \%$ & 1.176 & 1.083 & 1.086 & 0.0080 \\
\hline 0.0100 & $2.33 \%$ & 1.086 & 1.061 & 1.024 & 0.1618 \\
\hline
\end{tabular}

\section{Panel B: Firms with a High Compared to Low Price-to-Sales Ratio}

For all Thresholds of the form $\mathrm{T}=\mathrm{N} \mathrm{x} 10^{\mathrm{K}}$, for integers $\mathrm{N}$ (1 through 9 ) and $\mathrm{K}$ (5 through 10)

\begin{tabular}{|c|c|c|c|c|c|}
\hline $\begin{array}{l}\text { Bin Width (in } \\
\text { terms of the } \\
\text { common log of } \\
\text { revenue) }\end{array}$ & $\begin{array}{l}\text { Bin Width (in } \\
\text { terms of } \\
\text { percentage of } \\
\text { revenue) } \\
\end{array}$ & $\begin{array}{c}\text { Highest Price-to- } \\
\text { Sales Ratio Decile } \\
\text { ABOVE/BELOW } \\
\left(S_{j, H i g h \_P S}\right)\end{array}$ & $\begin{array}{c}\text { Lowest Price-to- } \\
\text { Sales Ratio Decile } \\
\text { ABOVE/BELOW } \\
\left(S_{j, L o w \_P S}\right)\end{array}$ & $\begin{array}{c}\text { Ratio of Ratios } \\
\text { (Vj= } \\
S_{j, H i g h \_P S} / \\
\left.S_{j, L o w \_P S}\right) \\
\end{array}$ & $\begin{array}{c}\text { Approximate } \\
\text { Randomization } \\
\text { p-value } \\
\end{array}$ \\
\hline 0.0010 & $0.23 \%$ & 2.175 & 1.329 & 1.637 & 0.0387 \\
\hline 0.0025 & $0.58 \%$ & 1.308 & 1.090 & 1.200 & 0.0928 \\
\hline 0.0050 & $1.16 \%$ & 1.233 & 1.032 & 1.195 & 0.0179 \\
\hline 0.0100 & $2.33 \%$ & 1.160 & 1.051 & 1.104 & 0.0583 \\
\hline
\end{tabular}

This table presents the results of approximate randomization tests estimating the significance of the difference in the Threshold Effect for high and low past revenue growth firms and price-to-sales ratios, where high (low) growth (P/S ratio) is defined as the top (bottom) percentage revenue growth (P/S ratio) decile. Each panel presents results for the full set of all Base-Ten thresholds and provides statistics for four logged bin widths, including the ratio of the number of observations in the bins just above and below the threshold points as well as the ratio of these ratios (the test statistic used to generate the approximate randomization p-value). Approximate randomization p-values significant at the $5 \%$ level bolded. 


\section{Table 8. Threshold Firm-Years and Changes in News Coverage}

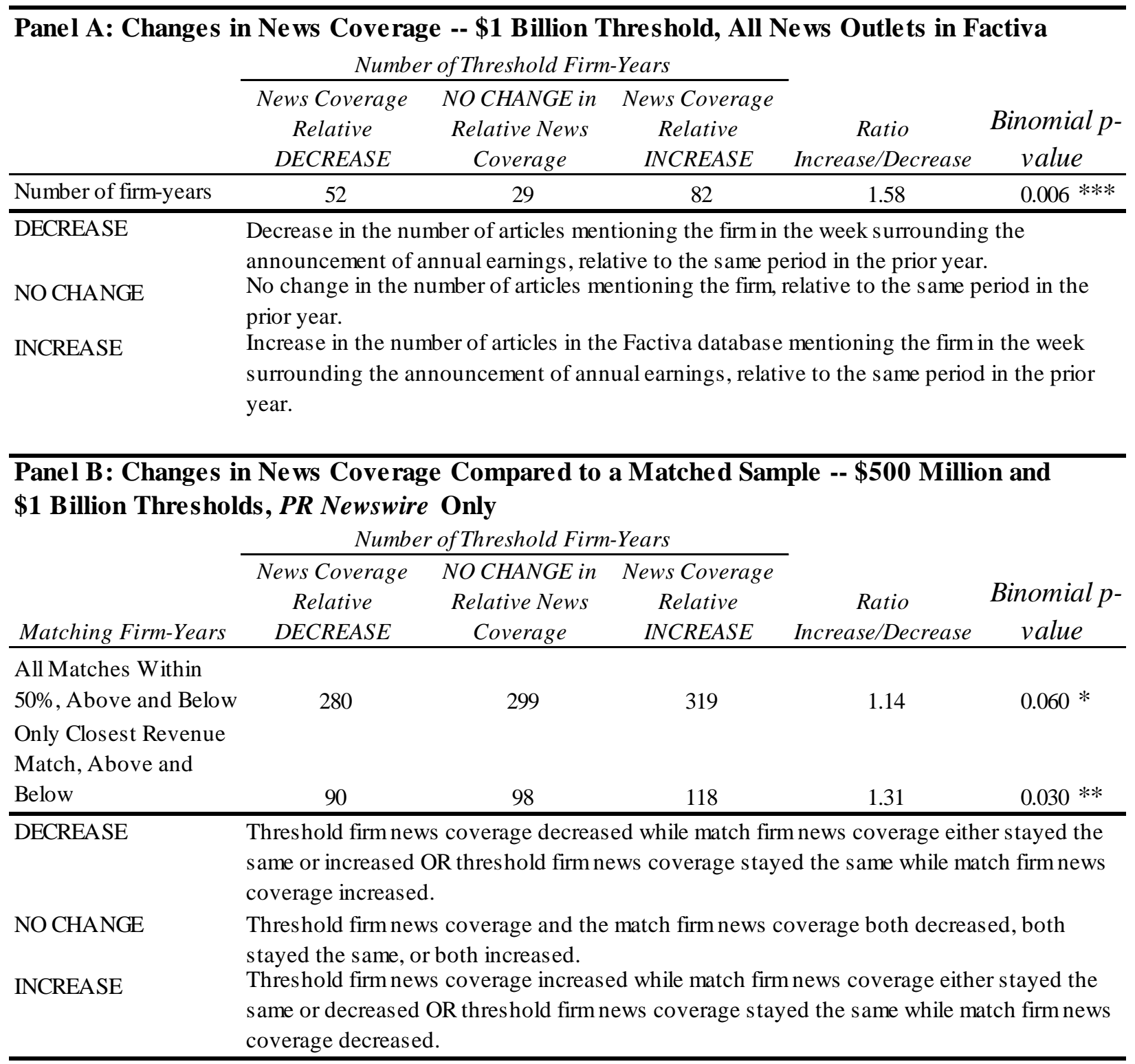

$* * *, * * *$ Significant at the $0.01,0.05,0.10$ level. 
Table 9. Threshold Firm-Years and Future Revenue Growth

\begin{tabular}{|c|c|c|c|c|c|c|}
\hline \multicolumn{7}{|c|}{ Panel A: Changes in Revenue Growth -- Difference in Means } \\
\hline & Last Year & Next Year & $\begin{array}{c}t \text {-statistic } \\
\text { WRS-statistic }\end{array}$ & Last Year & Next Year & $\begin{array}{c}t \text {-statistic } \\
\text { WRS-statistic }\end{array}$ \\
\hline \$1 Billion Threshold & & & & & & \\
\hline & $=248$ & & & $\mathrm{n}=301$ & & \\
\hline mean & $10.6 \%$ & $9.8 \%$ & -0.419 & $14.5 \%$ & $6.4 \%$ & $-5.309 * * *$ \\
\hline median $^{\mathrm{a}}$ & $8.4 \%$ & $8.7 \%$ & -0.058 & $10.3 \%$ & $6.8 \%$ & $-3.848 * * *$ \\
\hline
\end{tabular}

The t-statistics are from a parametric difference test between the Last Year and Next Year revenue growth rates.

The WRS-statistics are from a nonparamentric difference test, the Wilcoxon Rank-Sum Test, between the Last Year and Next Year revenue growth rates.

${ }^{a}$ Note that the BELOW WRS-statistic is negative even though the Next Year median is greater than the Last Year median. Strictly speaking, the Wilcoxon Rank-Sum Test is not a test of a difference in medians but instead is a test of a difference in distributions.

The BELOW firm-years are those with revenue below the threshold but within $2.33 \%$ of the threshold.

The ABOVE firm-years are those with revenue above the threshold but within $2.33 \%$ of the threshold.

Panel B: Changes in Revenue Growth -- Matched-Pair Comparison
\begin{tabular}{ccccc} 
Number of Near-Threshold Firm-Years \\
\cline { 2 - 4 } \\
Revenue & SAME & Revenue & \\
Growth Rate & Relative & Growth Rate & Ratio \\
Relative & Revenue & Relative & Increasel & Binomial \\
DECREASE & Growth Rate & INCREASE & Decrease & p-value \\
\hline
\end{tabular}

Just BELOW \$1 billion Threshold

All Matches Within

$10 \%$, Above and

Below

307

720

314

1.02

0.595

Just ABOVE \$1 billion Threshold

All Matches Within

$10 \%$, Above and

$\begin{array}{llllll}\text { Below } & 389 & 871 & 250 & 0.64 & 0.000^{* * * *}\end{array}$

DECREASE Near-threshold firm revenue growth rate decreased while match firm revenue growth rate increased.

SAME Near-threshold firm revenue growth rate and the match firm revenue growth rate both decreased or both increased.

INCREASE Near-threshold firm revenue growth rate increased while match firm revenue growth rate decreased.

*** Significant at the 0.01 level. 